\title{
System Transformation in Patient-Centered Medical Home (PCMH): Variable Impact on Chronically Ill Patients' Utilization
}

\author{
Caroline S. Carlin, PhD, Thomas J. Flottemesch, PhD, Leif I. Solberg, MD, \\ and Ann M. Werner, BS
}

Background: Research connecting patient-centered medical homes (PCMHs) with improved quality and reduced utilization is inconsistent, possibly because individual domains of change, and the stage of change, are not incorporated in the research design. The objective of this study was to examine the association between stage and domain of change and patterns of health care utilization.

Methods: This was a cross-sectional observational study that including 87 Minnesota clinics certified as medical homes. Patients included those receiving management for diabetes or cardiovascular disease with insurance coverage by payers participating in the study. PCMH transformation stage was defined by practice systems in place, with measurements summarized in 5 domains. Health care utilization was measured by total utilization, frequency of outpatient visits and prescriptions, and occurrence of inpatient and emergency department visits.

Results: PCMH transformation was associated with few changes in utilization, but there were important differences by the underlying domains of change. We demonstrate meaningful differences in the impact of PCMH transformation by diagnosis cohort and comorbidity status of the patient.

Conclusions: Because the association of health care utilization with PCMH transformation varied by transformation domain and patient diagnosis, practice leaders need to be supported by research incorporating detailed measures of PCMH transformation. (J Am Board Fam Med 2016;29:482-495.)

Keywords: Cardiovascular Diseases, Comorbidity, Cross-Sectional Studies, Diabetes Mellitus, Disease Management, Emergency Departments, Inpatients, Insurance Coverage, Minnesota, Outpatients, Patient-Centered Care, Research Design

In an effort to improve the quality and efficiency of care in the United States, the patient-centered medical home (PCMH) has become a focus of attention, including several demonstrations in the Affordable Care Act of 2010. The PCMH is a way of organizing primary care in a team-based health

This article was externally peer reviewed.

Submitted 20 November 2015; revised 18 April 2016; accepted 22 April 2016.

From the Medica Research Institute, Minneapolis, MN (CSC); and the HealthPartners Institute for Education and Research, Bloomington, MN (TJF, LIS, AMW).

Funding: This work was funded by grant 1R18HS019161 from the Agency for Healthcare Research and Quality (primary investigator, Leif Solberg).

Conflict of interest: none declared.

Corresponding author: Caroline S. Carlin, $\mathrm{PhD}$, Medica Research Institute, Mail Route CW105, PO Box 9310, Minneapolis, MN 55440-9310 (E-mail: caroline. carlin@medica.com). care delivery model that emphasizes care coordination and communication to improve patient outcomes. While some research suggests that PCMHs can improve quality and reduce costs, the evidence is not strong and provides little guidance for redesigning primary care practice. Much of this evidence is summarized in a series of review articles ${ }^{1-4}$ that found some weak evidence for improvement in care processes but an inconclusive or inconsistent impact on patterns of health care utilization. There is some evidence that the impact of PCMHs is greater for sicker patients. ${ }^{2,5,6}$

Part of the reason for this uncertainty may lie in the fact that the transformation of a medical practice to a $\mathrm{PCMH}$ is a complex process that takes time to pass through several stages. Significant changes are needed in technology, roles, and responsibilities, requiring staff buy-in and the devel- 
opment of a supportive culture and shared decision-making processes. ${ }^{7}$ It is important to recognize that transformation is a continuum, with an overlap between clinics recognized as medical homes and those not yet so recognized. ${ }^{8}$

The majority of the literature connecting PCMH transformation with health care utilization does not recognize this complexity of transformation. Most of the literature uses a binary measure of PCMH certification in a cross-sectional framework $^{5,9}$ or categorizes clinics as PCMHs or control sites in a difference-in-differences framework. ${ }^{10-13}$ The literature examining the impact of individual elements of PCMH transformation is sparse (eg, Philpot et $\mathrm{al}^{14}$ ). In an early study capturing the spectrum of transformation, Flottemesch et $\mathrm{al}^{6} \mathrm{ex}-$ amined variation in practice structure at baseline (2005) and its association with cost of care over the subsequent 5 years for clinics from a single system that were eventually recognized as level III $\mathrm{Na}$ tional Committee for Quality Assurance (NCQA)certified PCMHs. They used the Physician Practice Connections-Research Survey (PPC-RS) to measure practice structure. Flottemesch et al found that for complex patients, higher baseline PPC-RS scores were associated with lower total costs, lower outpatient costs, fewer inpatient days, and less emergency department (ED) use.

\section{Objectives}

We want to help both practice leaders and researchers by examining the association between clinic transformation to a PCMH and health care utilization in a sample of patients with chronic disease (diabetes mellitus [DM] and cardiovascular disease [CVD]). Importantly, we examine these associations across 5 domains of change, highlighting differences by patient population.

\section{Methods \\ Study Setting}

In 2010, as a result of state health reform legislation enacted in 2008, the Minnesota Department of Human Services and the Minnesota Department of Health published standards for voluntary clinic certification as a Health Care Home (HCH), Minnesota's term for PCMHs. These Minnesota standards have a different focus than those published by NCQA in 2008 and 2011. Burton et $\mathrm{al}^{15}$ note that the NCQA standards are heavily weighted toward health information technology; by contrast, Minnesota standards focus little on health information technology because state law already requires that providers use e-prescribing (2011 and later) and have interoperable electronic health records (2015 and later). The Minnesota process focuses on quality improvement activities, continuous access, care coordination, a searchable electronic registry, and individualized care plans. Minnesota's certification process also includes meeting annually updated quality targets.

Our study setting focused on Minnesota clinics certified as HCHs by October 2011 that also participated in a separate research survey using the PPC-RS instrument to measure the presence of practice systems associated with PCMHs. These practice systems are grouped in 5 domains, shown in Table 1. "Health care organization" includes elements of performance measurement and quality improvement; "delivery system redesign" focuses on structural changes in staffing and managing patient visits; the "clinical information systems" domain captures disease registries, care checklists, and tracking of the care process; "decision support" measures the guidelines, reminders, and alerts available to the clinician; and "self-management support" assesses patient communication, education, and support in chronic disease management. The PPC-RS contains questions asking about the presence of systems in each of these domains, each with 3 answer options: "present and works well" (1 point), "present but needs improvement" (0.5 points), and "not present" (0 points). Some of these questions (indicated by an asterisk in Table 1) were asked separately by chronic condition: DM, CVD, depression, and asthma.

The survey process was completed in early 2011, close to the time of $\mathrm{HCH}$ certification for these clinics, which began in July 2010. Clinic medical leaders were asked about current practice systems in their clinic and the state of those systems 3 years earlier (before certification). Thus each clinic has 2 sets of scores, before and after certification. We rescaled the total scores so that the maximum response, across clinics and time, was 100 . We captured the subscores for these 5 domains, rescaling in the same manner so that the maximum score within each domain was 100 .

This study was reviewed and approved before the initiation of the survey, and was monitored 
Table 1. Elements of Physician Practice Connections-Readiness Survey, by Domain

\begin{tabular}{|c|c|}
\hline Chronic Care Model Domain & Elements of the Physician Practice Connections-Readiness Survey \\
\hline Health care organization & $\begin{array}{l}\text { Individual provider feedback } \\
\text { Performance measurement } \\
\text { Formal quality improvement activities }\end{array}$ \\
\hline Delivery system redesign & $\begin{array}{l}\text { Advanced access visits } \\
\text { Primary care teams } \\
\text { Scheduling system for physician continuity } \\
\text { Non-MD educator* } \\
\text { Nurse manager* } \\
\text { Previsit planning* } \\
\text { After-visit follow-up* } \\
\text { Missed appointments follow-up* }\end{array}$ \\
\hline Clinical information systems & $\begin{array}{l}\text { Disease registry* } \\
\text { Problem lists } \\
\text { Medication lists } \\
\text { Process flow sheets* } \\
\text { Checklists of tests or interventions* } \\
\text { Patient assessment questionnaire* } \\
\text { Clinical test tracking } \\
\text { Referral tracking }\end{array}$ \\
\hline Decision Support & $\begin{array}{l}\text { Clinical guidelines* } \\
\text { Clinical guidelines preventive services } \\
\text { Clinician reminders for chronic illness care* } \\
\text { Clinician reminders for preventive services } \\
\text { Clinician reminders for risk assessments } \\
\text { Clinician reminders for counseling } \\
\text { Abnormal radiology and lab test alerts } \\
\text { Abnormal test protocols }\end{array}$ \\
\hline Self-management support & $\begin{array}{l}\text { Patient reminders for chronic illness care* } \\
\text { Patient reminders for preventive services } \\
\text { Self-management programs for risk factors } \\
\text { Individualized patient education about chronic illness* } \\
\text { Self-management programs for chronic illness* } \\
\text { Self-management plans/materials for chronic illness* } \\
\text { Electronic information/communication with patients } \\
\text { Systematic risk factor screening }\end{array}$ \\
\hline
\end{tabular}

*Asked separately for diabetes, cardiovascular disease, depression, and asthma.

throughout the project, by the HealthPartners Institutional Review Board.

\section{Patient Population in Participating Clinics}

The data were collected through a unique datapooling effort, with assistance from Minnesota Community Measurement (MNCM), combining claims data for the large majority of patients in a typical primary care practice. MNCM, founded by 6 Minnesota health plans and the Minnesota Medical Association, provides transparent public reports of quality measures for all clinics in Minne- sota. Their earliest public report (2004) summarized quality of care metrics for patients with specific chronic conditions and preventive care measures. By 2007, these chronic conditions included DM and CVD.

We leveraged the data collection process used by MNCM to identify the sample of patients for our study. Clinics participating in the MNCM initiative identified patients for whom they were actively managing chronic illnesses and provided payer information to MNCM. Thus MNCM had a list of patients with DM or CVD for the 87 clinics com- 
pleting the PPC-RS. Based on this list, the 3 largest health plans in the region and the Minnesota Department of Human Services contributed to the research team de-identified administrative data for these patients from their commercial, Medicare, and Medicaid files for calendar year 2010. These data were merged with PPC-RS responses by the research team. The payers provided only complete claims to the research team; we have no information on missing data. Our experience is that incomplete claims are rare because of rigorous claims adjudication.

\section{Study Design and Quantitative Variables}

This is a cross-sectional observational study. While we had PPC-RS measures from 2 time points, we had patient utilization measures only for calendar year 2010. Total utilization was measured using patient encounters multiplied by total cost relative resource value (TCRRV) units. TCRRV units ${ }^{16}$ are based on Centers for Medicare and Medicaid Services' relative value units by Current Procedural Terminology 4 code, inpatient diagnosis-related groups, and ambulatory payment classification weights. The TCRRV units function as standardized fees for all procedures, hospital admissions, and prescriptions that are independent of place of service, type of insurance coverage, or year.

We also modeled utilization by type of care, including the number of primary care outpatient visits, the number of outpatient prescriptions, the probability of $\geq 1$ inpatient visit, and the probability of $\geq 1$ ED visit. Primary care visits were defined as outpatient visits with providers (including nurse practitioners and physicians assistants) in the following specialties: family medicine, internal medicine, general practice, geriatric medicine, and obstetrics/gynecology. Outpatient prescriptions were defined as a count of all medications prescribed and filled on an outpatient basis with a minimum of an initial 60-day or two 30-day fills. ${ }^{17}$

Our main independent variable of interest measured the maturity of the PCMH transformation process, based on normalized PPC-RS scores. We categorized each clinic's stage of PCMH transformation as early, intermediate, or late. Early stage clinics had a normalized PPC-RS score $<50$ in both time periods. Intermediate-stage clinics had a prior score $<50$ but a current score of $\geq 50$. Latestage clinics had a score $\geq 50$ in both time periods. We selected the normalized score of 50 because, across time and clinics, this was close to the median normalized PPC-RS score. We created analogous transformation measures in each of the 5 domains. Variables used as controls included a patient's age, sex, number of additional comorbidities, and fixed effects for plan type (commercial, Medicare, Medicaid, special-needs Medicaid) and each of the payers. The comorbidity count includes DM (CVD only), chronic obstructive pulmonary disease, asthma, depression, congestive heart failure, and coronary artery disease (the latter 2 for DM only). These diagnoses were identified based on International Classification of Diseases, 9th Revision, code history.

\section{Statistical Methods}

We modeled each observed utilization measure $Y_{i}$ as a function of the maturity of clinic transformation and the control variables. Specifically, for individual $i$ treated in clinic $j$, we modeled

$y_{i}=\alpha_{1}$ Intermediate $_{j}+\alpha_{2}$ Late $_{j}+x_{i}^{\prime} \beta+\delta_{c}+\gamma_{p}$

$$
+\varepsilon_{i}
$$

The variables Intermediate ${ }_{j}$ and Late $_{j}$ are binary indicators of the PCMH transformation stage for clinic $j$, relative to the omitted early stage. The vector $x_{i}$ captures the characteristics of the patients, and $\delta_{c}$ and $\gamma_{p}$ are the coverage type $c$ and payor $p$ fixed effects. The error terms $\varepsilon_{i}$ are assumed to be normally distributed and are clustered within clinic. All models were estimated using StataMP 11.

The relationship between the observed $Y_{i}$ and the modeled variable $y_{i}$ depends on the type of utilization. Because total utilization, number of prescriptions, and number of outpatient visits are highly skewed, we used a $\log$ transformation and modeled $y_{i}=\ln \left(Y_{i}\right)$. The binary indicators of $\geq 1$ inpatient admission or $\geq 1 \mathrm{ED}$ visit were modeled using a probit regression, so $y_{i}$ represents a latent variable that determines the observed $Y_{i}$. The probit model assumes that $Y_{i}=0$ is observed when $y_{i}<$ 0 , and $Y_{i}=1$ is observed when $y_{i} \geq 0$.

Our parameters of interest are $\alpha_{1}$ and $\alpha_{2}$, associated with $\mathrm{PCMH}$ transformation. To enhance interpretation, we present marginal effects of transformation. For the log-transformed models (total utilization, number of scripts, number of outpatient visits), these marginal effects are simply the parameters, interpreted as an approximate percentage 
change in the outcome as a clinic moved from the early stage to either the intermediate or late stage. For example, if the outpatient visit regression estimated $\alpha_{1}=-0.05$ and $\alpha_{2}=-0.10$, on average we would expect to see a $5 \%$ decrease in visits when a clinic moved from the early to intermediate stage and a $10 \%$ decrease in visits when a clinic moved from the early to the late stage. For the probit models (inpatient admissions and ED visits), we used the regression results to predict the percentage-point change in the probability of $\geq 1$ inpatient admission or ED visit when transformation maturity changed. For example, if we predict a $25 \%$ average probability of inpatient admission at the early stage and a $20 \%$ average probability of inpatient admission at the late stage, the marginal effect would be -0.05 , or a 5 percentage-point decrease in average probability, when the clinic moved from the early to the late stage.

In addition to the main effect of clinic transformation stage, we also estimated how the impact of transformation maturity varied by the comorbidity status of the patient, by transformation domain, and by the combination of comorbidity and domain.

\section{Results}

\section{Descriptive Data}

Table 2 describes the distribution of outcome and control variables. The CVD population had higher rates of overall utilization, and higher rates of inpatient and ED use, than the DM population. The CVD population was older, whereas the DM population included a larger proportion of women. Consistent with these differences, a patient with CVD was more likely to be covered by Medicare and less likely to be covered by Medicaid.

Table 3 summarizes our independent variable of interest, transformation maturity of the patients' primary care clinics, which was similar between the 2 populations. We see in Table 3 that health care organization transformation and decision support transformation were the domains with the largest fraction of patients in clinics achieving late-stage transformation. Recall that the health care organization domain focuses on provider feedback and quality improvement activities, whereas the decision support domain focuses on clinical guidelines and clinician notifications. Thus both of these domains focus on support and feedback for clinicians rather than patients.
Table 2. Summary Statistics of Variables by Study Population

\begin{tabular}{|c|c|c|}
\hline & Diabetes Mellitus & $\begin{array}{c}\text { Cardiovascular } \\
\text { Disease }\end{array}$ \\
\hline Observations, $\mathrm{n}$ & 9,032 & 2,280 \\
\hline $\begin{array}{c}\text { Overall Utilization in } \\
\text { TCRRVs, } \\
\text { mean (SD) }\end{array}$ & $18,956(34,703)$ & $27,796(55,104)$ \\
\hline $\begin{array}{l}\text { Prescriptions, mean } \\
\text { (SD) }\end{array}$ & $50.9(44.7)$ & $46.2(41.9)$ \\
\hline $\begin{array}{r}\text { Outpatient Visits, } \\
\text { mean (SD) }\end{array}$ & $45.6(69.0)$ & $45.0(56.6)$ \\
\hline $\begin{array}{l}\geq 1 \text { Inpatient } \\
\text { admission }\end{array}$ & $1,348(14.9)$ & $604(26.5)$ \\
\hline $\begin{array}{l}\geq 1 \text { Emergency } \\
\text { department } \\
\text { visits }\end{array}$ & $1,983(22.0)$ & $615(27.0)$ \\
\hline \multicolumn{3}{|l|}{ Age (years) } \\
\hline$<40$ & $751(8.3)$ & $23(1.0)$ \\
\hline $40-49$ & $1,533(17.0)$ & $183(8.0)$ \\
\hline $50-54$ & $1,432(15.9)$ & $289(12.7)$ \\
\hline $55-59$ & $1683(18.6)$ & $414(18.2)$ \\
\hline $60-64$ & $1,868(20.7)$ & $600(26.3)$ \\
\hline$\geq 65$ & $1,765(19.5)$ & $771(33.8)$ \\
\hline Female sex & $4,537(50.2)$ & $726(31.8)$ \\
\hline \multicolumn{3}{|l|}{ Comorbidities } \\
\hline 0 & $6,144(68.0)$ & $304(52.1)$ \\
\hline 1 & $2,129(23.6)$ & $1,319(34.3)$ \\
\hline$\geq 2$ & $759(8.4)$ & $657(13.6)$ \\
\hline \multicolumn{3}{|l|}{ Type of coverage } \\
\hline Commercial & $5,450(60.3)$ & $1,278(56.0)$ \\
\hline Medicare & $1,226(13.6)$ & $585(25.7)$ \\
\hline \multicolumn{3}{|l|}{ Medicaid } \\
\hline $\begin{array}{l}\text { Mothers and } \\
\text { children }\end{array}$ & $2,211(24.5)$ & $394(17.3)$ \\
\hline Special needs & $145(1.6)$ & $23(1.0)$ \\
\hline
\end{tabular}

Data are $\mathrm{n}(\%)$ unless otherwise indicated.

$\mathrm{SD}$, standard deviation; TCRRV, total cost relative resource value.

\section{Impact of Overall Maturity of PCMH Transformation}

The statistically insignificant marginal effects of overall PCMH transformation on total utilization are displayed in the top row of Figure 1 for the average patient and by the patient's comorbidity status. Recall that these marginal effects are parameters in a lognormal regression and can be interpreted as an approximate percentage change in total utilization. (Regression parameters are available from the corresponding author upon request; tables listing marginal effects are available in the Appendix online). Each cluster within these charts shows the marginal effect of intermediate- and late-stage $\mathrm{PCMH}$ transformation relative to early stage trans- 
Table 3. Distribution of Patients by Transformation Status of Their Primary Care Clinic

\begin{tabular}{|c|c|c|}
\hline $\begin{array}{l}\text { Transfer Stage, by } \\
\text { Clinic Type }\end{array}$ & $\begin{array}{l}\text { Diabetes } \\
\text { Mellitus }\end{array}$ & $\begin{array}{c}\text { Cardiovascular } \\
\text { Disease }\end{array}$ \\
\hline \multicolumn{3}{|l|}{ PPC-RS } \\
\hline Early & $1200(13.3)$ & $343(15.0)$ \\
\hline Intermediate & $5245(58.1)$ & $1305(57.3)$ \\
\hline Late & $2587(28.6)$ & $632(27.7)$ \\
\hline \multicolumn{3}{|l|}{$\begin{array}{l}\text { Health care } \\
\quad \text { organization }\end{array}$} \\
\hline Early & $455(5.1)$ & $102(4.5)$ \\
\hline Intermediate & $2351(26.0)$ & $584(25.6)$ \\
\hline Late & $6226(68.9)$ & $1594(69.9)$ \\
\hline \multicolumn{3}{|l|}{$\begin{array}{l}\text { Delivery system } \\
\text { redesign }\end{array}$} \\
\hline Early & $2632(29.2)$ & $756(33.1)$ \\
\hline Intermediate & $5123(56.7)$ & $1274(55.9)$ \\
\hline Late & $1277(14.1)$ & $250(11.0)$ \\
\hline \multicolumn{3}{|l|}{$\begin{array}{l}\text { Clinical } \\
\text { information } \\
\text { system }\end{array}$} \\
\hline Early & $1470(16.3)$ & $418(18.3)$ \\
\hline Intermediate & $4605(51.0)$ & $1168(51.2)$ \\
\hline Late & $2957(32.7)$ & $694(30.5)$ \\
\hline \multicolumn{3}{|l|}{ Decision support } \\
\hline Early & $688(7.6)$ & $241(10.6)$ \\
\hline Intermediate & $3528(39.1)$ & $787(34.5)$ \\
\hline Late & $4816(53.3)$ & $1252(54.9)$ \\
\hline \multicolumn{3}{|l|}{$\begin{array}{l}\text { Self-management } \\
\text { system }\end{array}$} \\
\hline Early & $1696(18.8)$ & $448(19.7)$ \\
\hline Intermediate & $4248(47.0)$ & $1088(47.7)$ \\
\hline Late & $3088(34.2)$ & 744 (32.6) \\
\hline
\end{tabular}

Data are $\mathrm{n}(\%)$.

PPC-RS, Physician Practice Connections-Readiness Survey.

formation. The results from the patients with DM are in the left columns, those from patients with CVD on the right. Within a chart, the first cluster shows the average impact across patients; the next 3 clusters break out the results by patient comorbidity status. While none of the marginal effects in these total utilization charts were statistically significant, in the CVD population the $U$-shaped pattern by comorbidity status was repeated in the marginal effects by type of care.

The next 4 rows of Figure 1 display these marginal effects by type of care: number of prescriptions, number of primary care outpatient visits, probability of inpatient visits, and probability of ED visits. As for the total utilization, the marginal effects for the number of prescriptions and outpatient visits are the parameters from a lognormal regression and should be interpreted as the approximate percentage change in the number of prescriptions. The marginal effects for the probabilities of inpatient and ED usage are computed from the regression results and should be interpreted as the percentage-point change in the probability of the occurrence of the type of care.

The most notable impact of PCMH transformation was a decrease in number of outpatient visits (row 3). Among patients with DM, the marginal effects of intermediate-stage transformation were stronger for patients with more comorbidities, whereas the late-stage marginal effects were more balanced across comorbidity status. All statistically significant results for patients with DM were in the range of $12 \%$ to $18 \%$ reductions in the number of outpatient visits. Among patients with CVD, we again found a $U$-shaped impact: PCMH transformation seems to reduce outpatient visits for the healthiest and sickest cohorts, ranging from a $20 \%$ to $34 \%$ reduction in the number of outpatient visits. The only other statistically significant impact of PCMH transformation was limited to ED visits for patients with CVD (row 5), where the 2 marginal effects that were statistically or marginally significant were consistent with a $U$-shaped impact of PCMH transformation on patients with CVD by comorbidity status.

\section{Maturity of PCMH Transformation by Domain}

We repeat the structure of Figure 1 to display the marginal effects of each domain of transformation: health care organization (Figure 2), delivery system redesign (Figure 3), clinical information systems (Figure 4), decision support (Figure 5), and selfmanagement support (Figure 6).

Figure 2 shows the marginal effects of increasing maturity in transformation of health care organization on total utilization were positive for patients with DM (left column), indicating increased utilization; the effects became larger as the patient's comorbidity status increased. These effects seem to be driven by increases in both outpatient and ED use. Few of the marginal effects of health care organization transformation were statistically significant for patients with CVD, but the $U$-shaped nature of the PPC-RS effects by comorbidity status was mirrored faintly in these health care organization results.

The most notable and consistent patterns in the marginal effect of delivery system redesign (Figure 
Figure 1. Marginal effect of increasing maturity in overall Physician Practice Connections-Research Survey (relative to early stage transformation) by patient comorbidity status. $* * \boldsymbol{P}<.05$; $* * \boldsymbol{P}<.01$. DM, diabetes mellitus; CVD, cardiovascular disease; IP, inpatient; ED, emergency department.
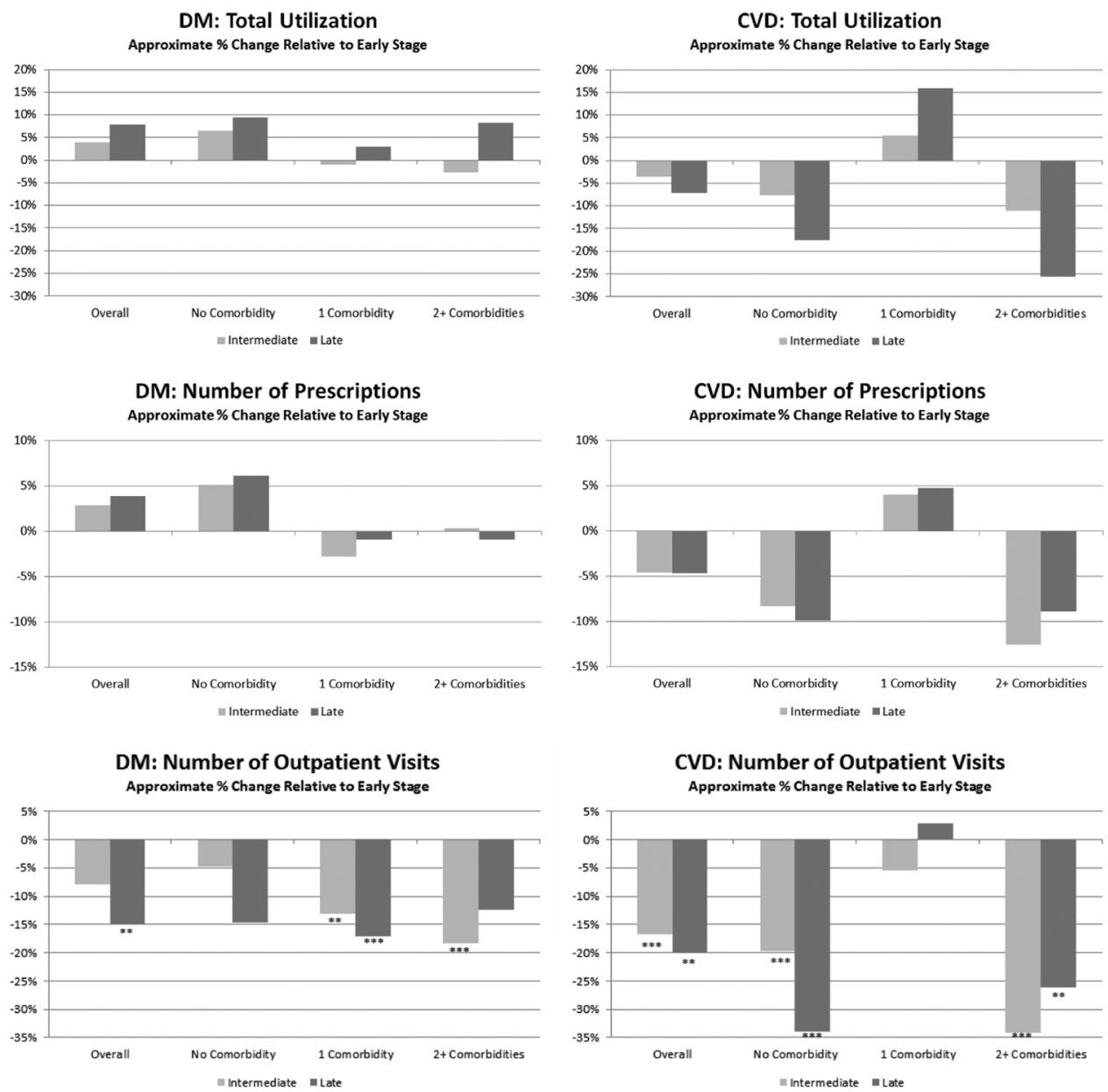

DM: Probability of One or More IP Admits Percentage-point change in Probability Relative to Early Stage

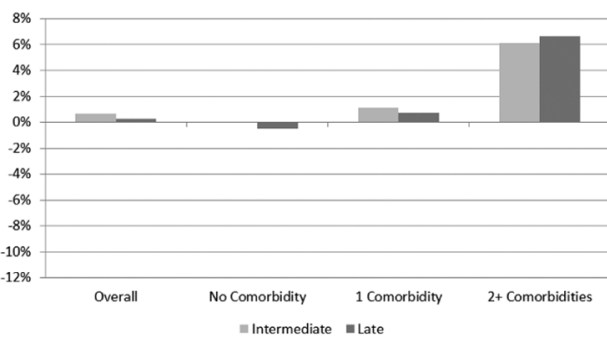

DM: Probability of One or More ED Visits Percentage-point change in Probability Relative to Early Stage
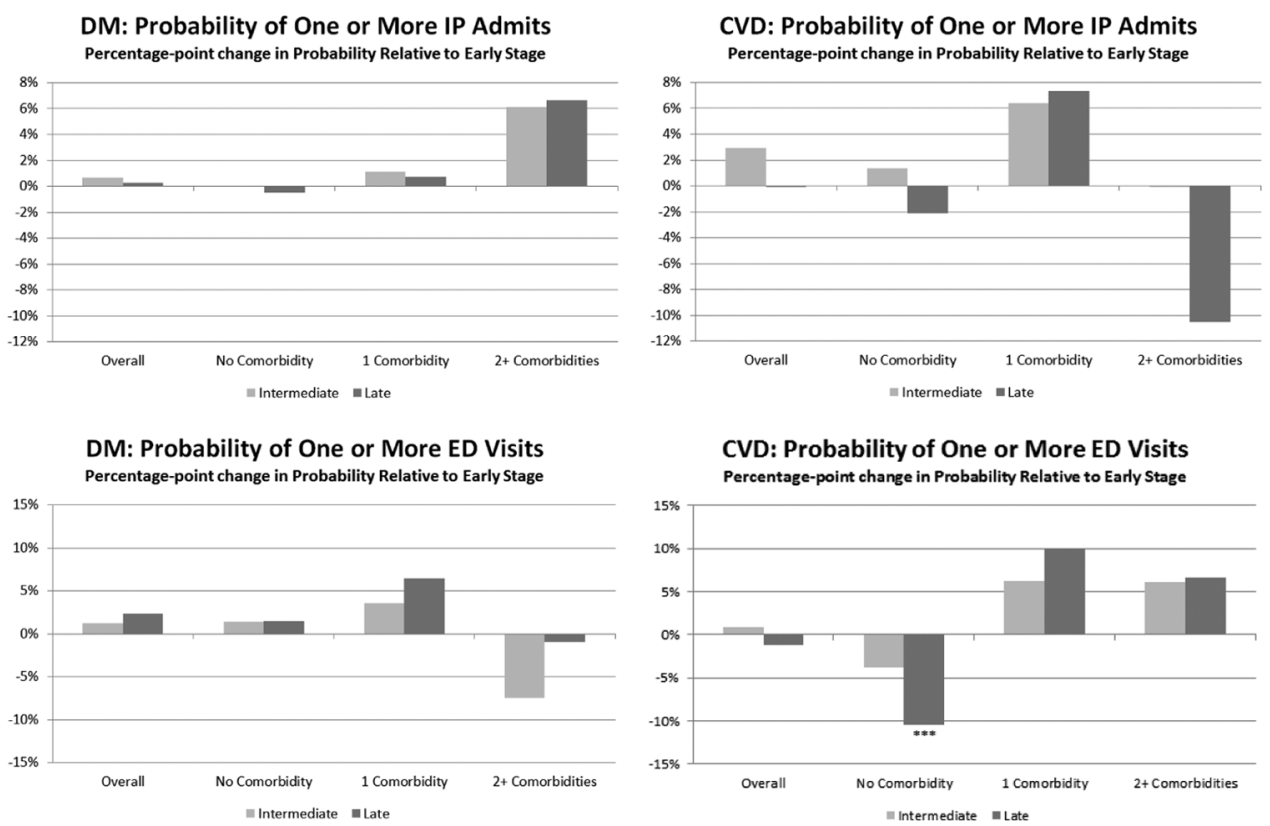
Figure 2. Marginal effect of increasing maturity in health care organization (relative to early stage transformation) by patient comorbidity status. ${ }^{*} \boldsymbol{P}<.05 ;{ }^{* * * P}<.01$. DM, diabetes mellitus; CVD, cardiovascular disease; HCO, health care organization; ED, emergency department; IP, inpatient.
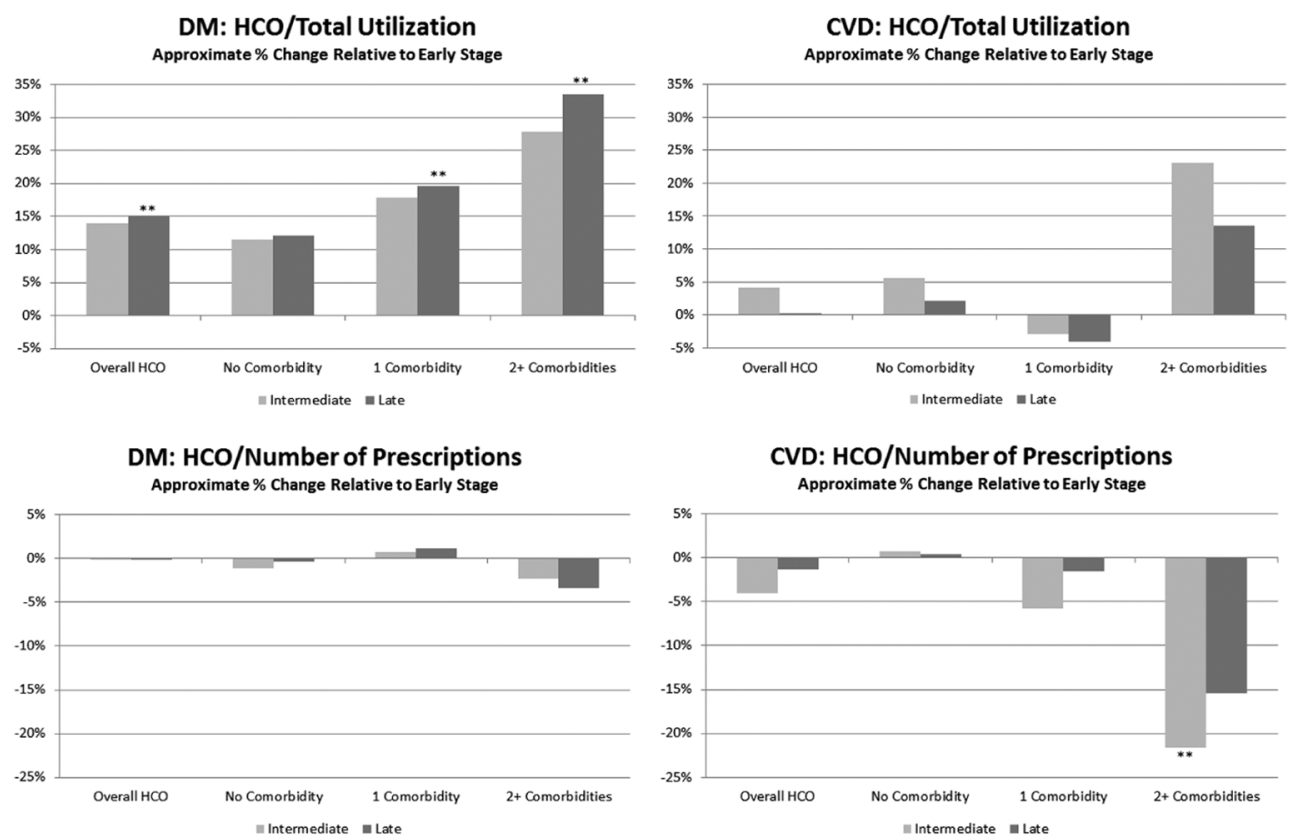

DM: HCO/Number of Outpatient Visits Approximate \% Change Relative to Early Stage

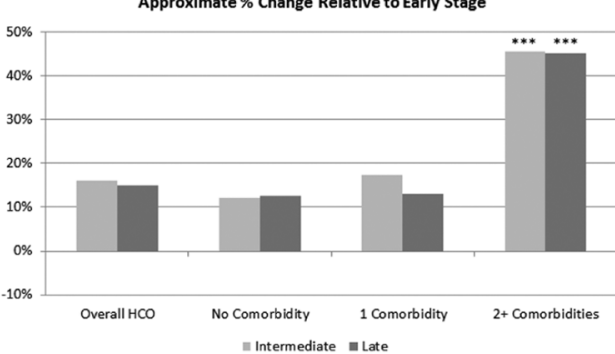

DM: HCO/Prob of One or More IP Admits Percentage-point change in Probability Relative to Early Stage

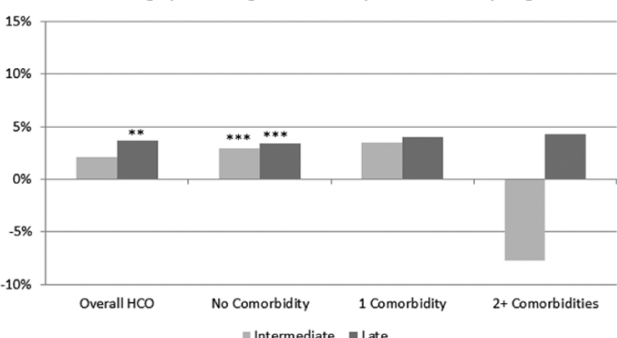

DM: HCO/Prob of One or More ED Visits Percentage-point change in Probability Relative to Early Stage
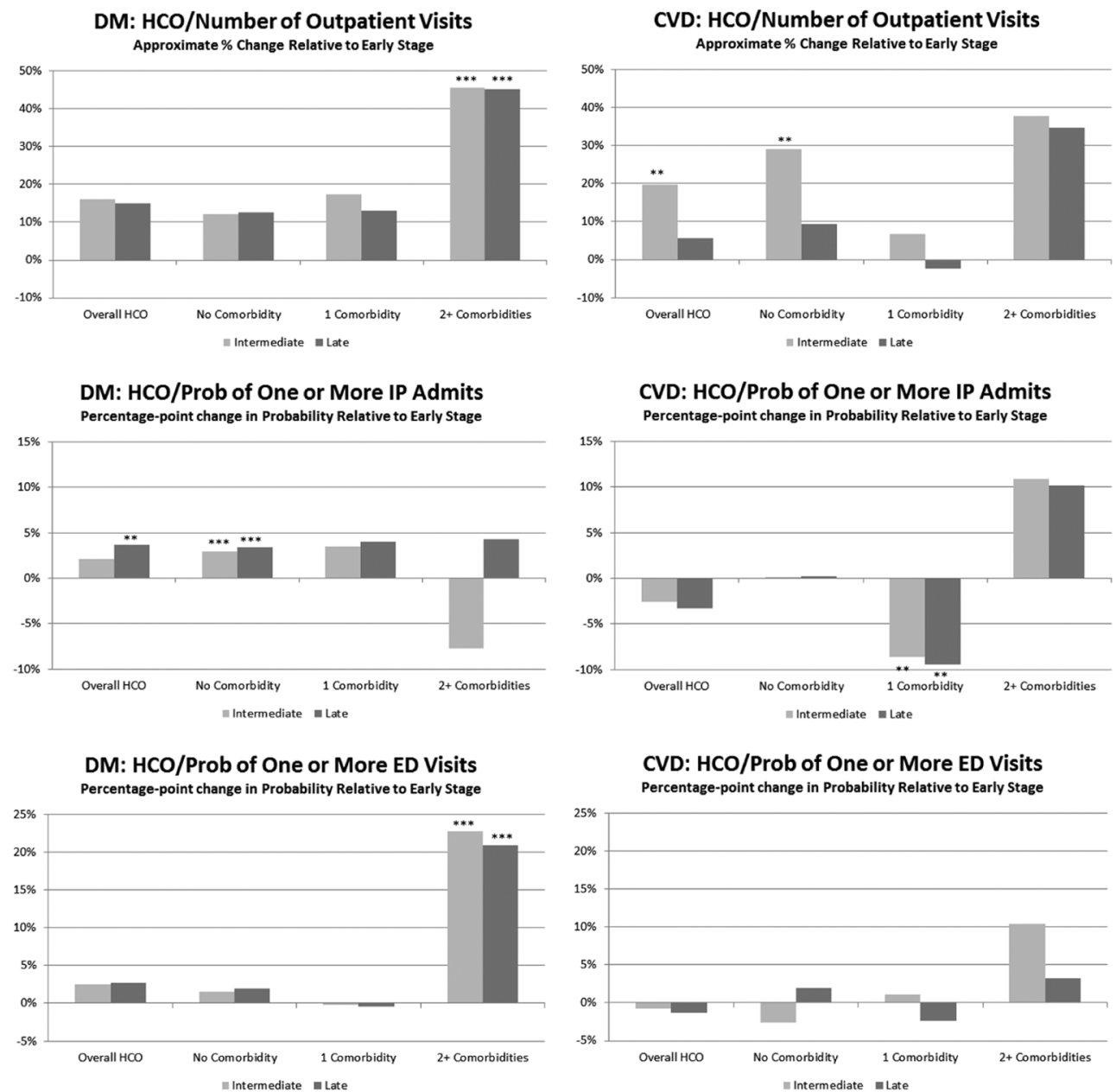

CVD: HCO/Prob of One or More ED Visits Percentage-point change in Probability Relative to Early Stage

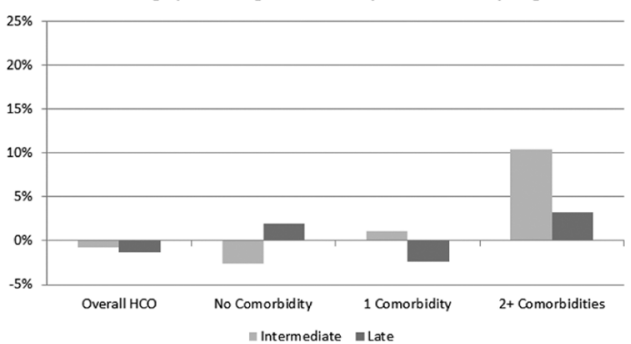


Figure 3. Marginal effect of increasing maturity in delivery system redesign (relative to early stage transformation) by patient comorbidity status. ${ }^{* * P}<.05$; ${ }^{* *} P<.01$. DM, diabetes mellitus; DSR, delivery system redesign; CVD, cardiovascular disease; IP, inpatient; ED, emergency department.
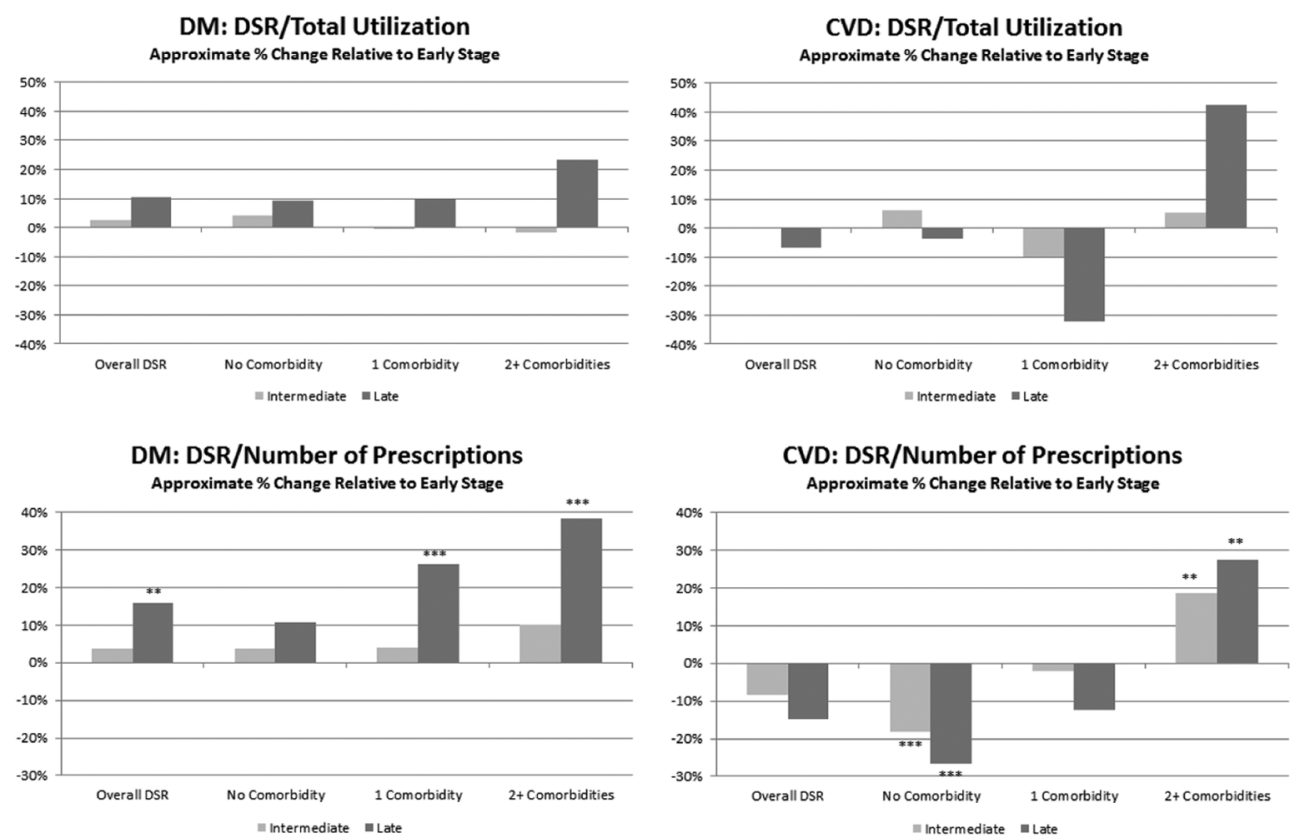

DM: DSR/Number of Outpatient Visits Approximate \% Change Relative to Early Stage

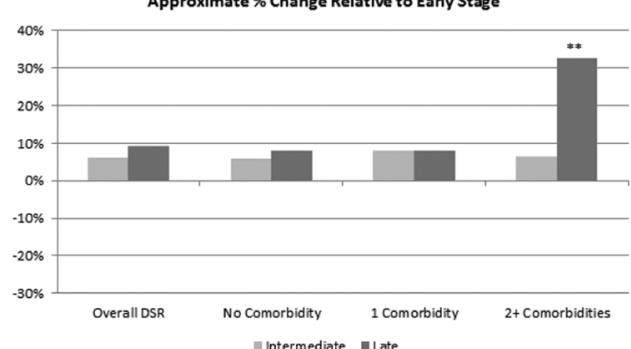

DM: DSR/Prob of One or More IP Admits Percentage-point change in Probability Relative to Early Stage
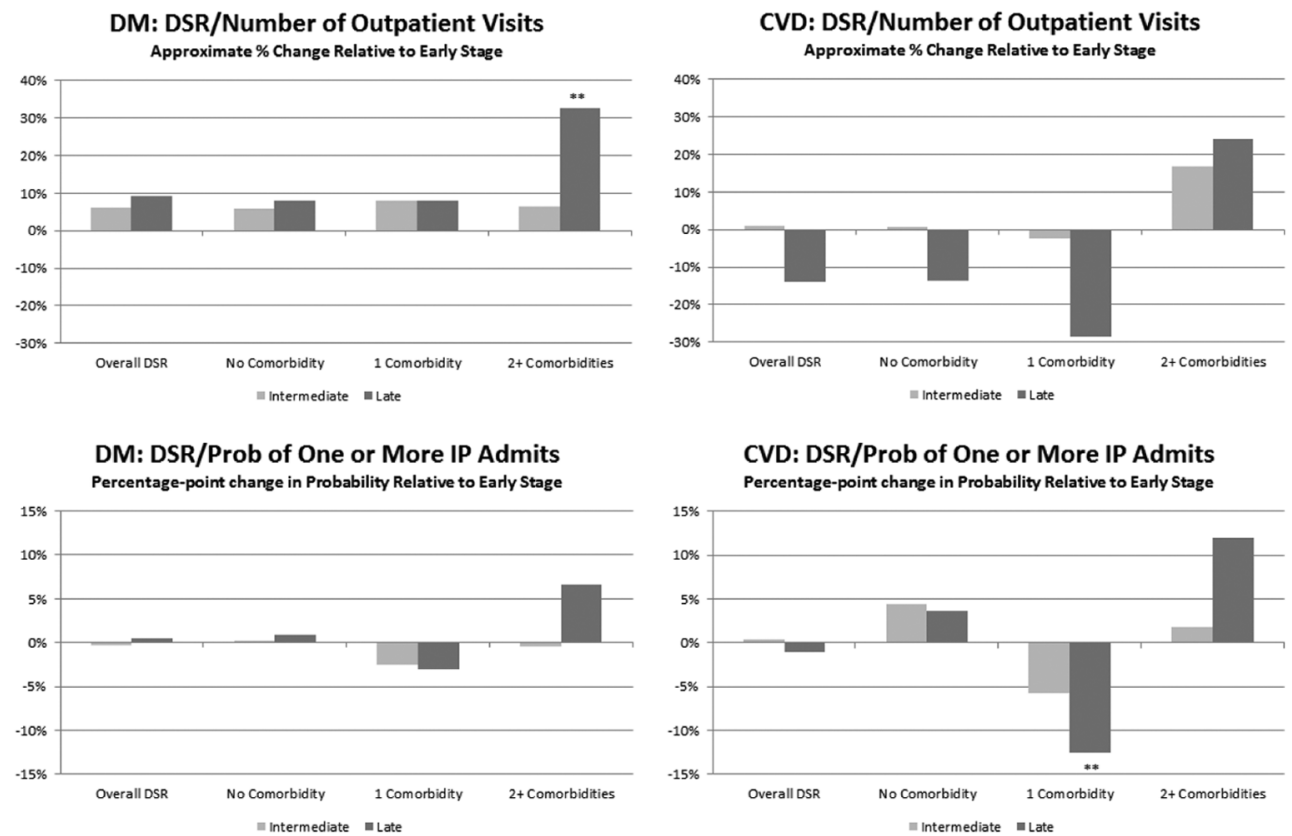

CVD: DSR/Prob of One or More IP Admits

Percentage-point change in Probability Relative to Early Stage

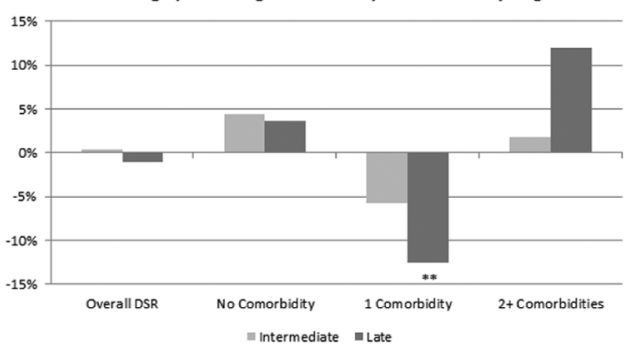

DM: DSR/Prob of One or More ED Visits Percentage-point change in Probability Relative to Early Stage

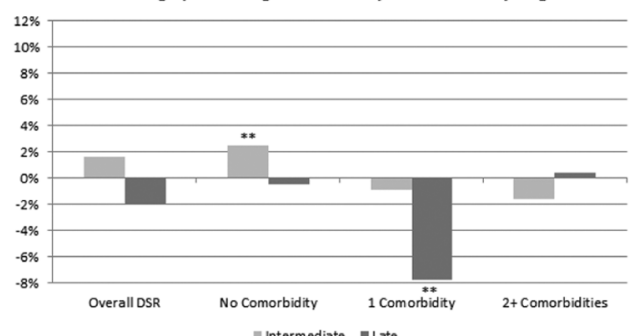

CVD: DSR/Prob of One or More ED Visits

Percentage-point change in Probability Relative to Early Stage

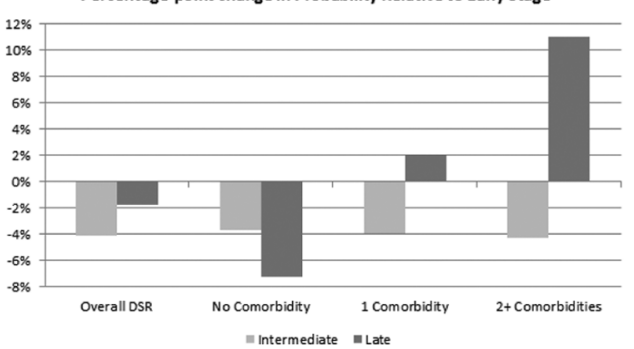


Figure 4. Marginal effect of increasing maturity in clinical information systems (relative to early stage transformation) by patient comorbidity status. ${ }^{* * P}<.05$; ${ }^{* * * P}<.01$. DM, diabetes mellitus; CIS, clinical information systems; CVD, cardiovascular disease; IP, inpatient; ED, emergency department.
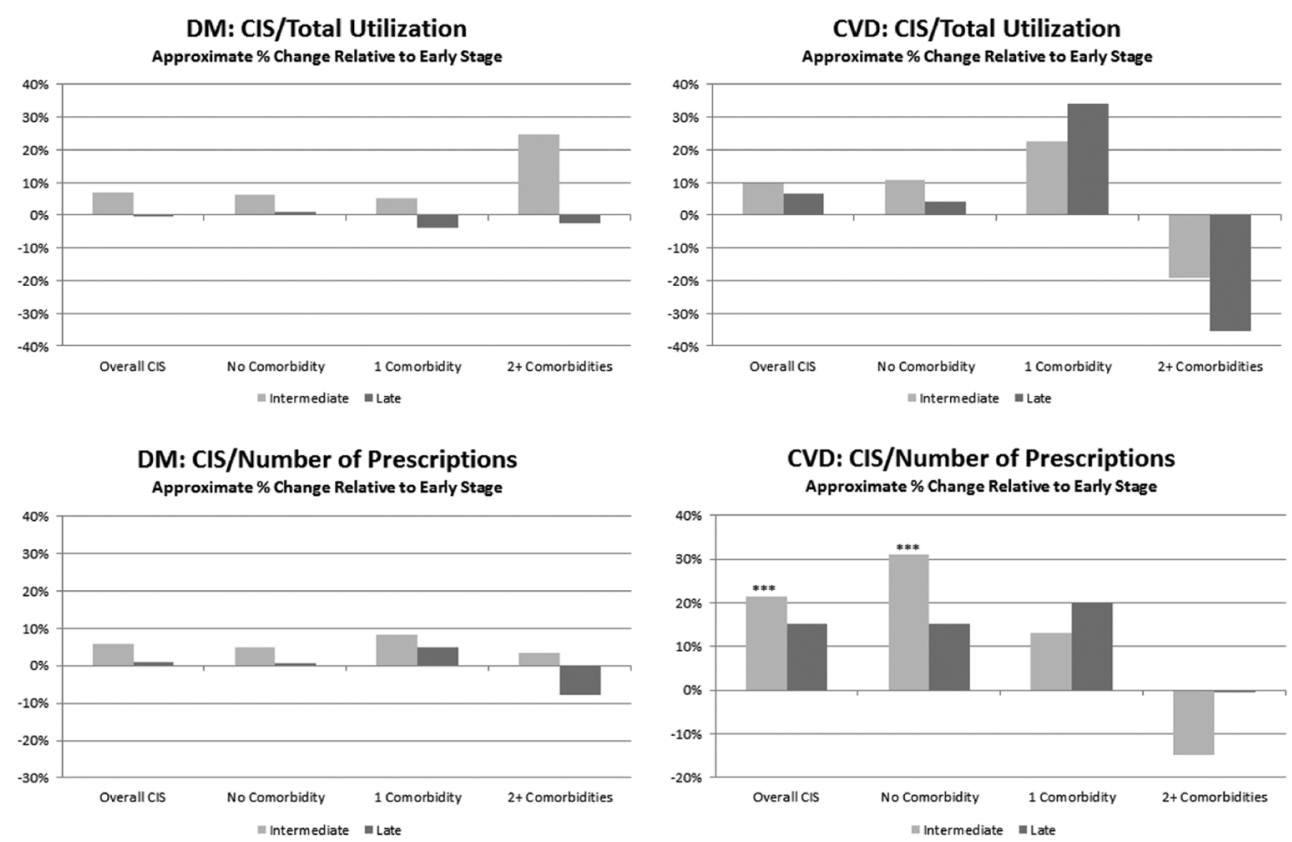

DM: CIS/Number of Outpatient Visits Approximate \% Change Relative to Early Stage

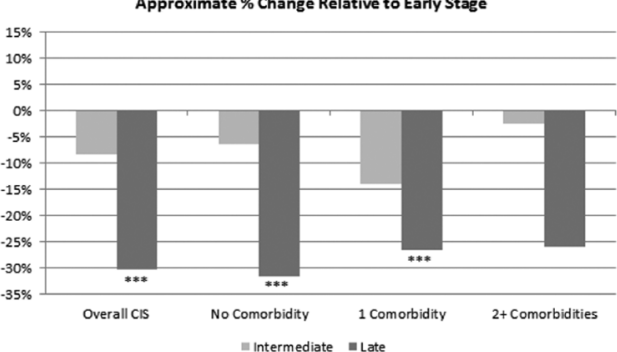

DM: CIS/Prob of One or More IP Admits Percentage-point change in Probability Relative to Early Stage

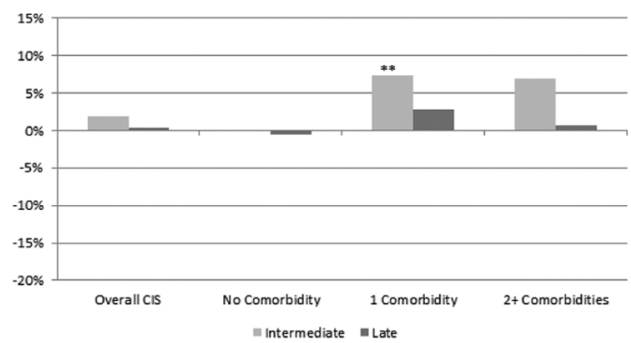

DM: CIS/Prob of One or More ED Visits
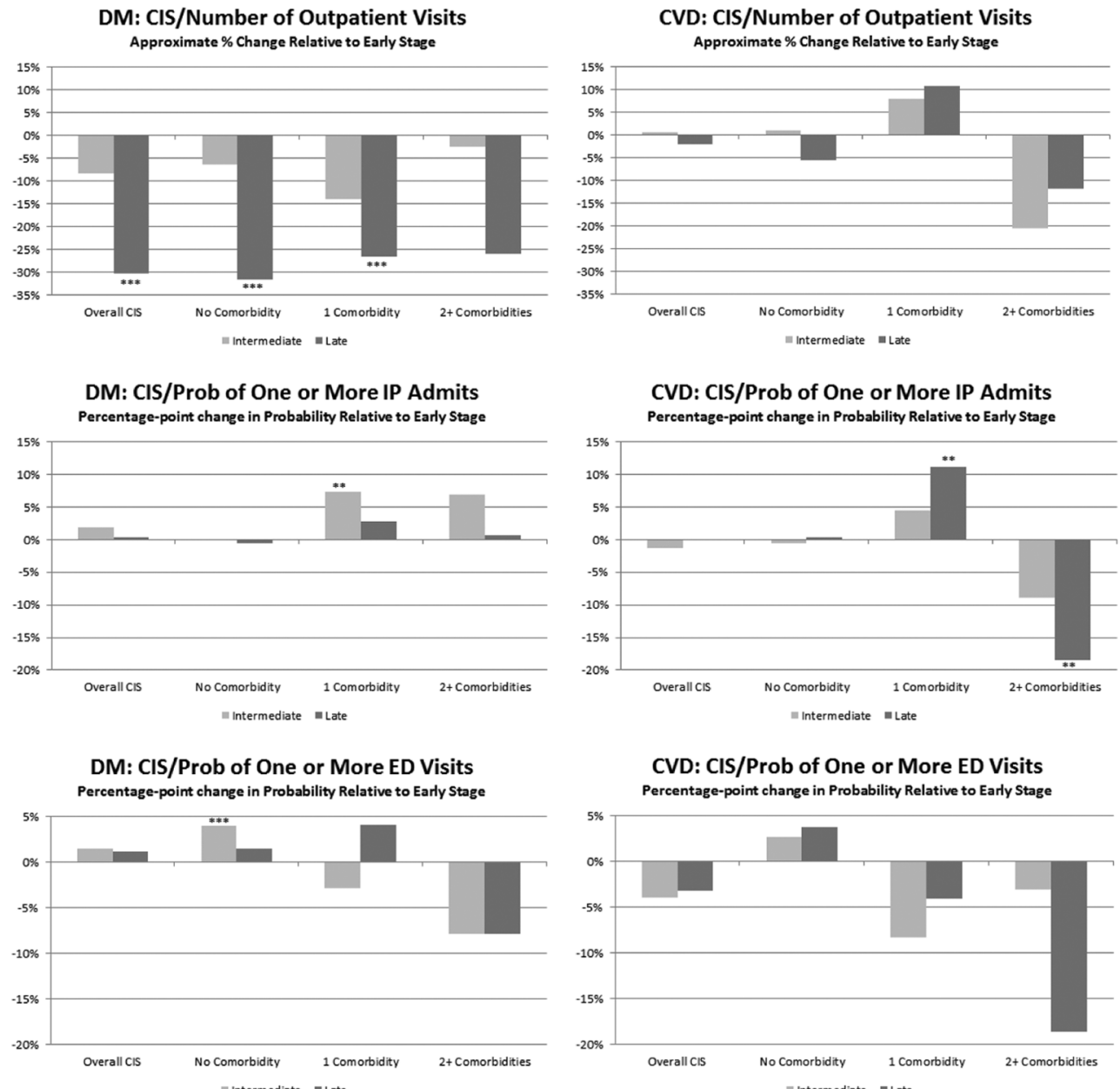

CVD: CIS/Prob of One or More IP Admits Percentage-point change in Probability Relative to Early Stage

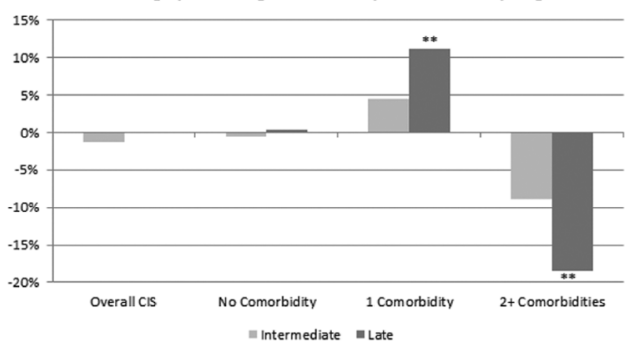

CVD: CIS/Prob of One or More ED Visits

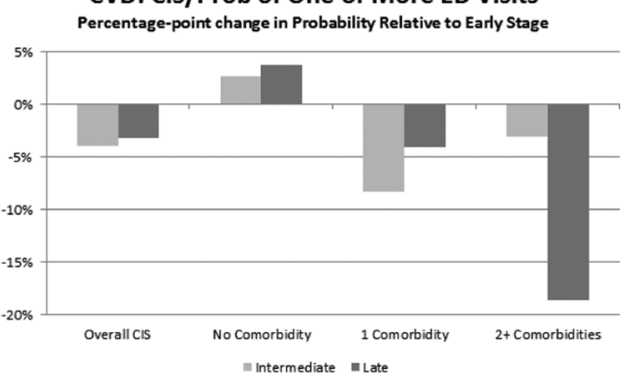


Figure 5. Marginal effect of increasing maturity in decision support (relative to early stage transformation) by patient comorbidity status. ${ }^{* * P}<.05$; ${ }^{* * * P}<.01$. DM, diabetes mellitus; DS, decision support; CVD, cardiovascular disease; IP, inpatient; ED, emergency department.
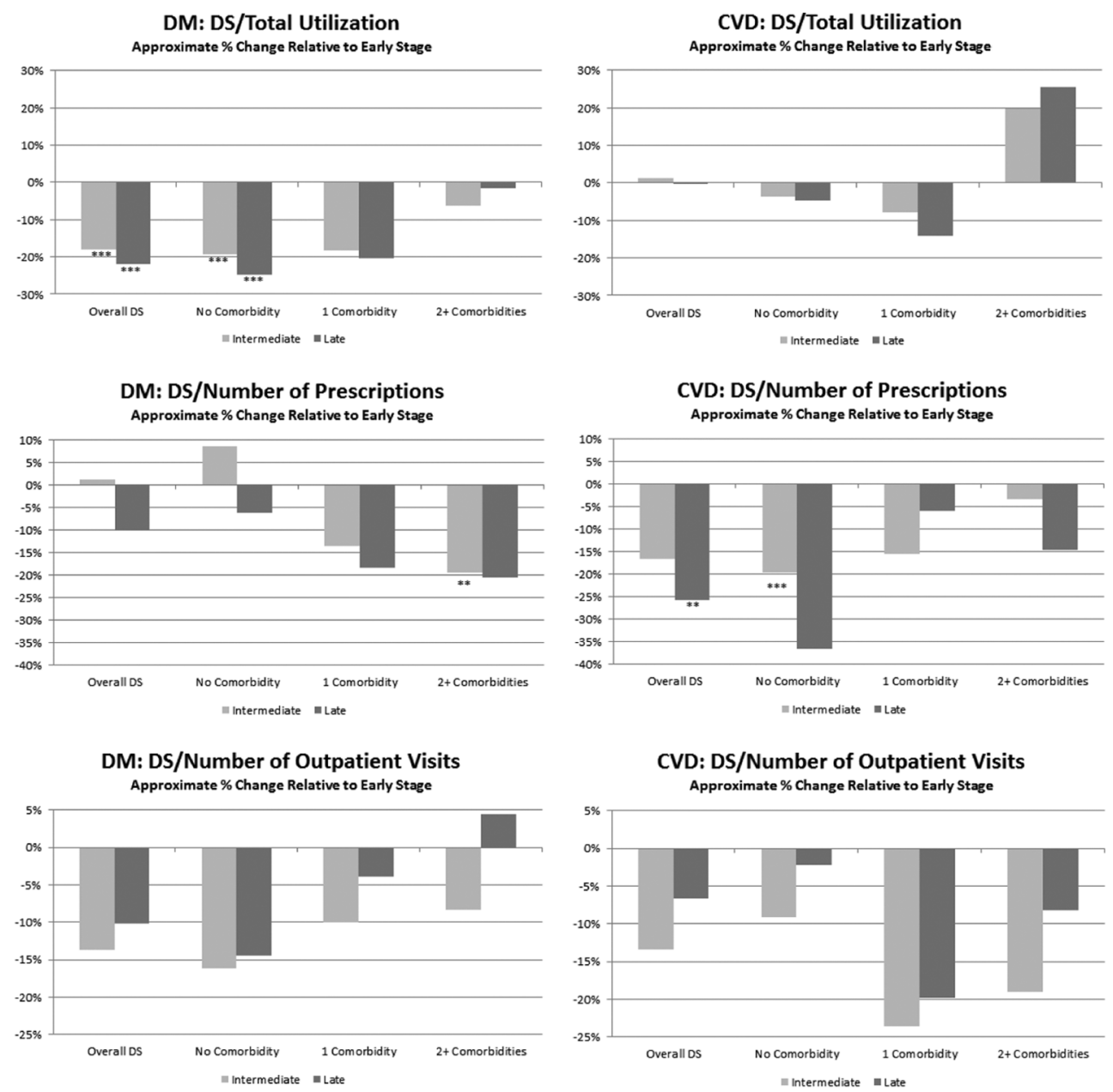

DM: DS/Prob of One or More IP Admits Percentage-point change in Probability Relative to Early Stage

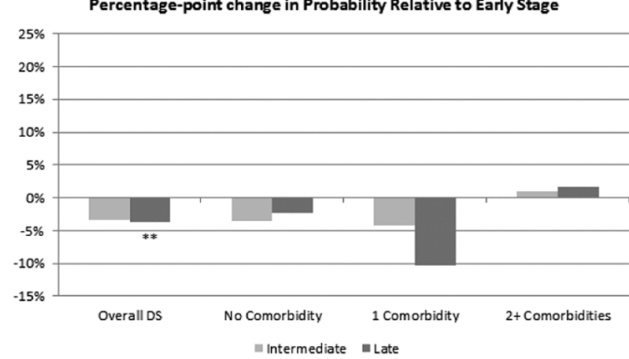

DM: DS/Prob of One or More ED Visits Percentage-point change in Probability Relative to Early Stage
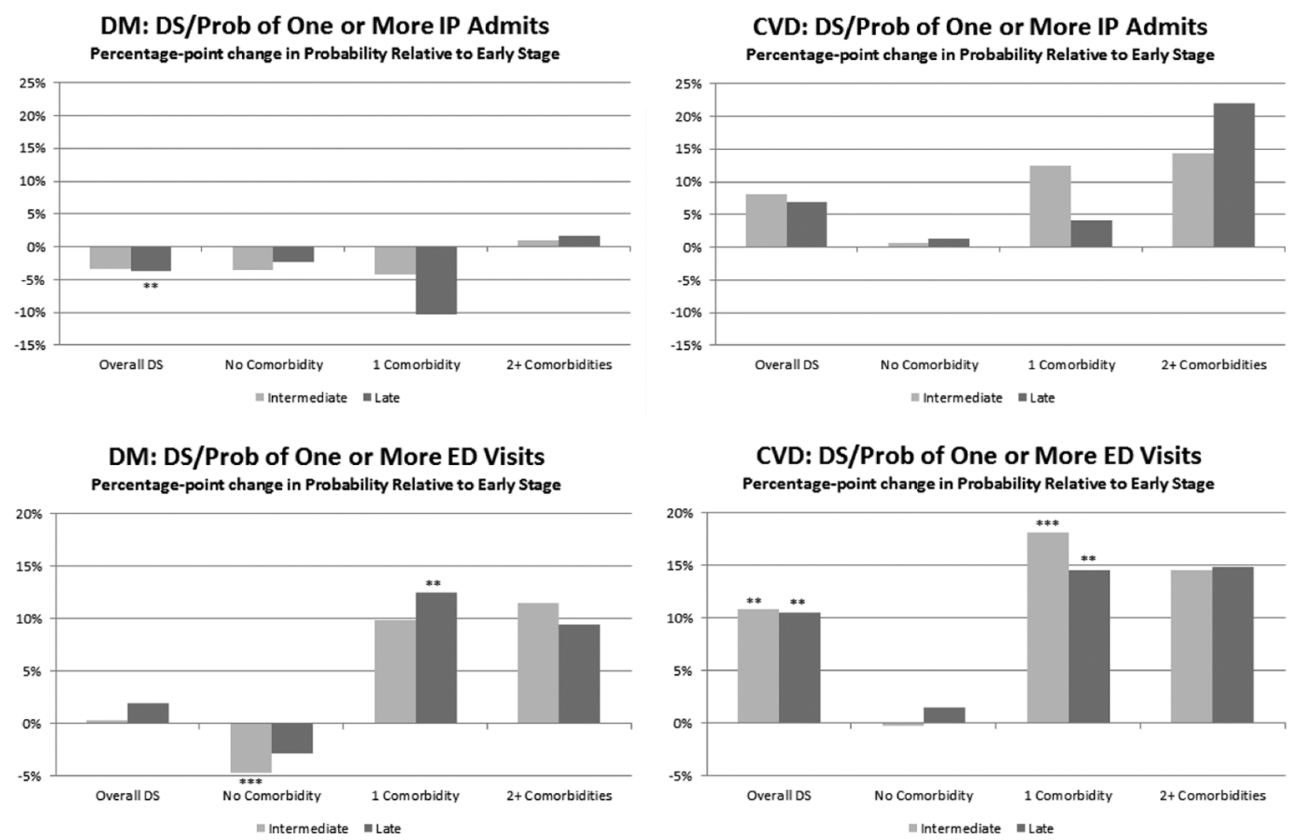
Figure 6. Marginal effect of increasing maturity in self-management support (relative to early stage transformation) by patient comorbidity status. ${ }^{* * P}<.05$; ${ }^{* * *} \boldsymbol{P}<.01$. DM, diabetes mellitus; SMS, selfmanagement support; CVD, cardiovascular disease; IP, inpatient; ED, emergency department.
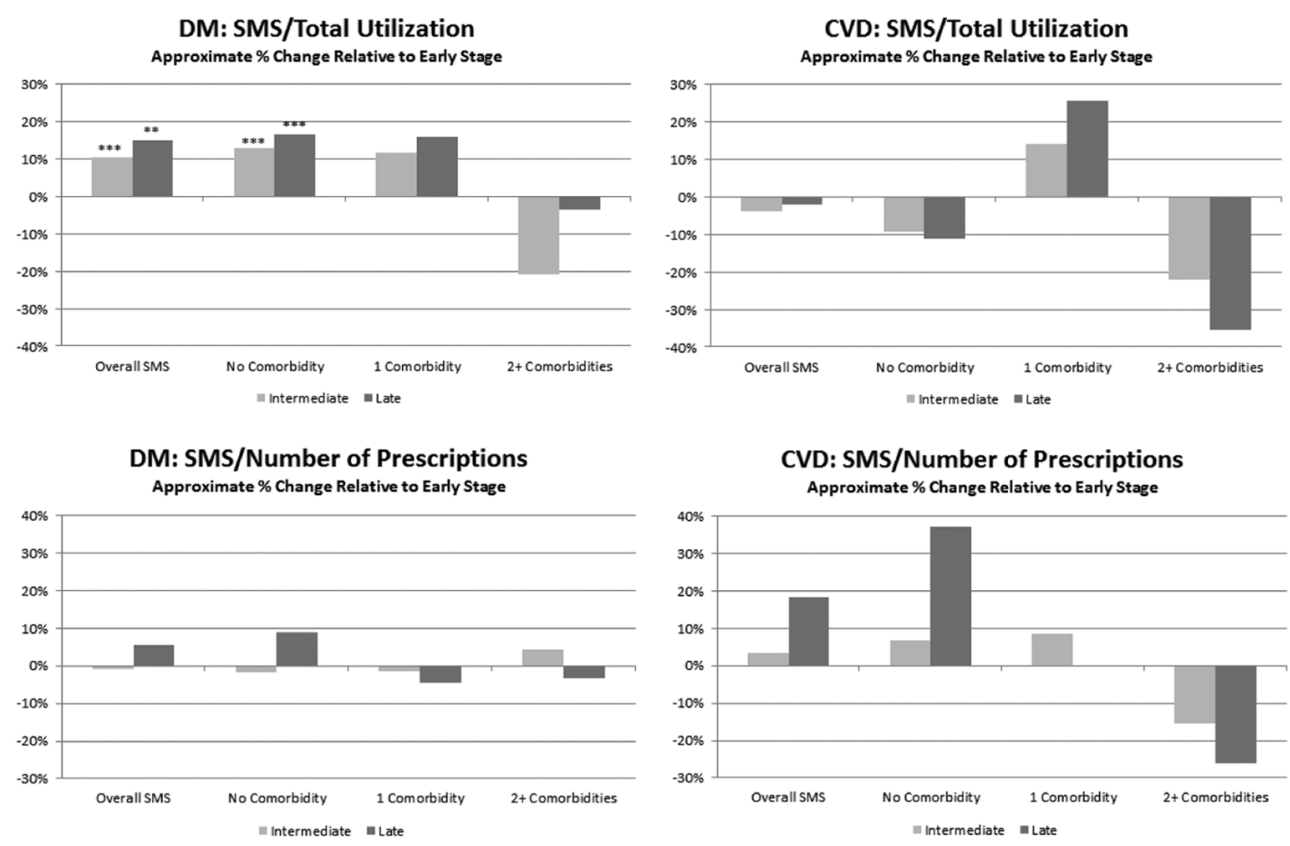

DM: SMS/Number of Outpatient Visits

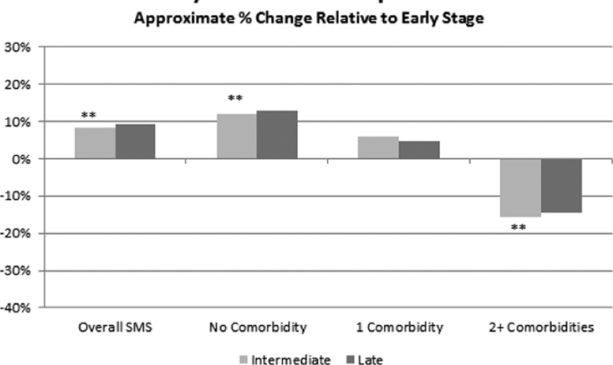

DM: SMS/Prob of One or More IP Admits Percentage-point change in Probability Relative to Early Stage

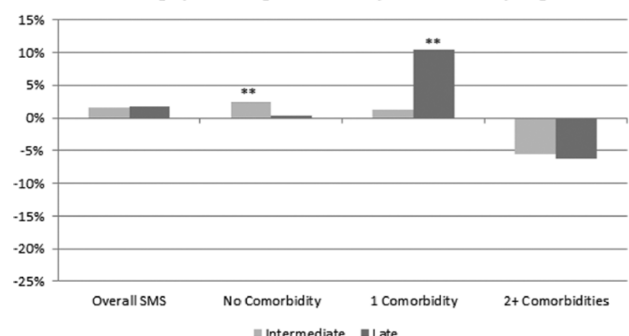

DM: SMS/Prob of One or More ED Visits Percentage-point change in Probability Relative to Early Stage
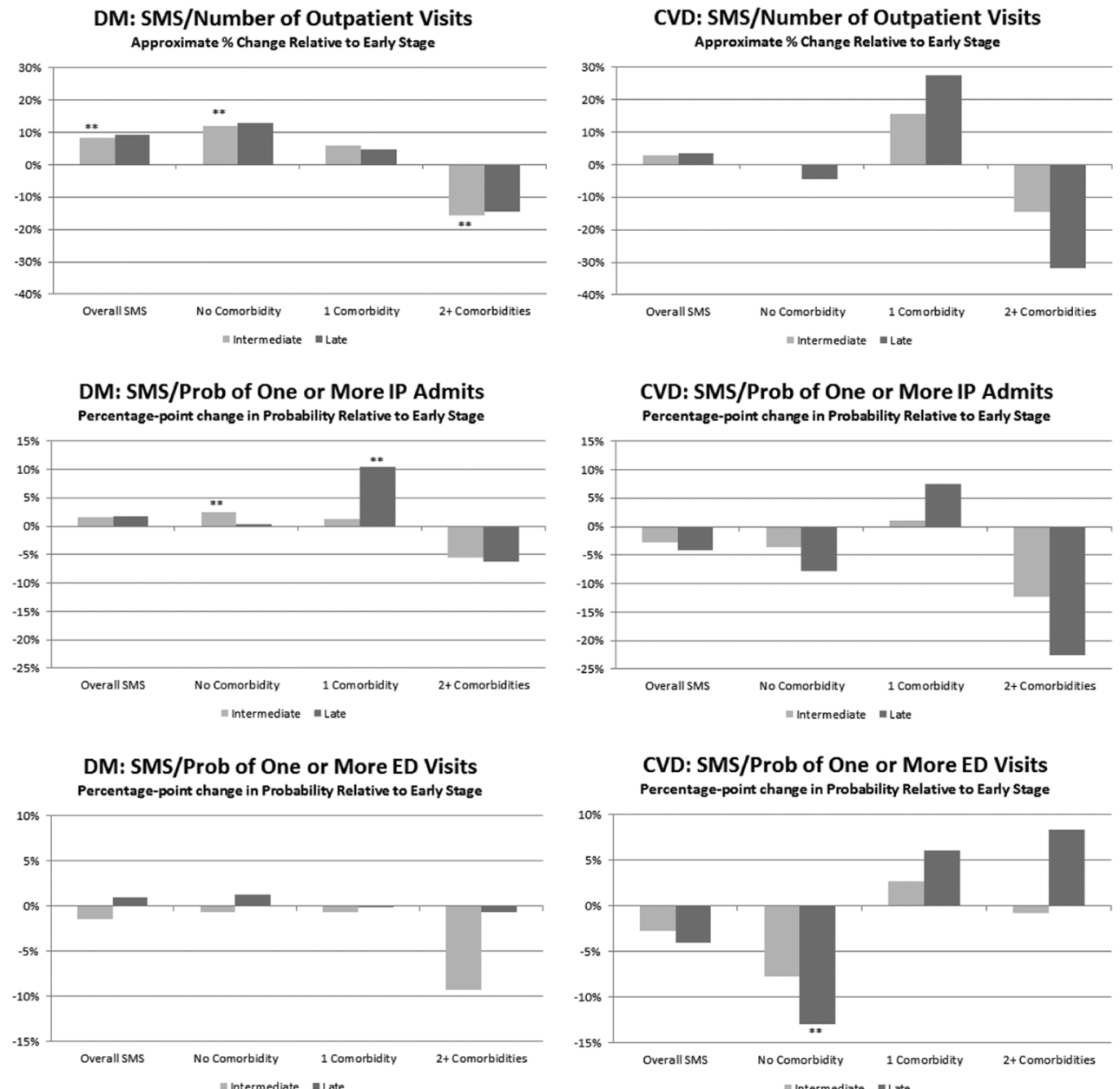

CVD: SMS/Prob of One or More IP Admits Percentage-point change in Probability Relative to Early Stage

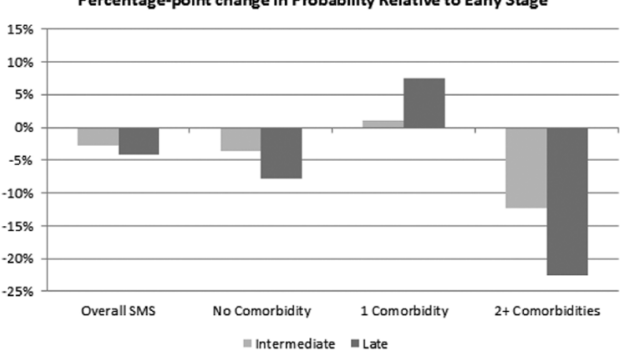

CVD: SMS/Prob of One or More ED Visits Percentage-point change in Probability Relative to Early Stage

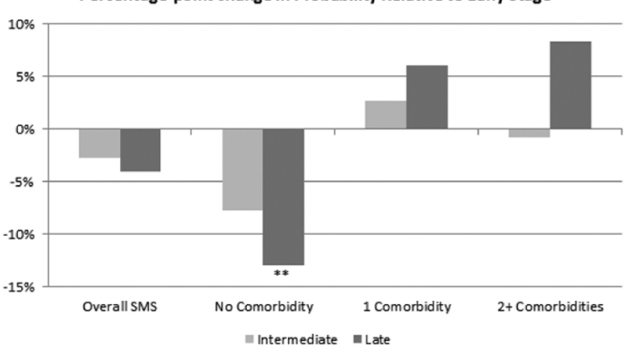


3) were present in prescription drug utilization. For patients with DM, there was a significant increase in the number of prescriptions when delivery system redesign was in late-stage transformation and comorbidities were present (a 38\% increase for the sickest cohort). Patients with CVD had increasing marginal effects, swinging from negative $(-18 \%$ to $-20 \%$ if no comorbidities) to positive $(+18 \%$ to $+20 \%$ if $\geq 2$ comorbidities) for both intermediateand late-stage transformation.

In late-stage transformation, the maturity of clinical information systems (Figure 4) drove significant reductions in the number of outpatient visits for patients with $\mathrm{DM}$, in the range of $25 \%$ to $35 \%$ reduction across all comorbidity statuses. The clinical information systems maturity for patients with CVD was associated with an increase in prescriptions, at least for the healthiest cohort.

Increase in decision support maturity (Figure 5) was associated with a $19 \%$ to $25 \%$ decline in total utilization for the healthiest patients with DM; this pattern was echoed in a decline in the number of outpatient visits, although it was not statistically significant. Both patients with DM and patients with CVD had fewer prescriptions as decision support matured; these concentrated among the sickest cohort for DM and the healthiest cohort for CVD. There was some evidence that mature decision support was associated with increased ED use by both populations.

Finally, self-management support maturity (Figure 6) was associated with increased utilization for the healthiest cohort, apparently driven by an increase in the number of outpatient visits. The results for the sickest cohort suggest that mature self-management support may reduce utilization as the health status of a patient with DM becomes more complex. There was little that was statistically significant for the CVD population, though mature self-management support was associated with reduced ED use among the healthiest CVD cohort.

\section{Discussion}

Previous reviews of the literature documenting the association of $\mathrm{PCMH}$ designation with health care utilization identify inconsistent and often negligible results, providing little guidance for practice leaders. Our work makes an important contribution by providing some insight into these inconsistencies, since it demonstrates that individual transfor- mation domains differ in their associations with utilization, and that these associations vary by diagnosis and comorbidity status of the patient population. While the only significant difference by overall PPC-RS was lower number of outpatient visits for clinics with greater maturity, the underlying variance in the impact of PCMH transformation by domain is instructive and highlights the importance of developing a body of research that takes into account the underlying domains of practice transformation and the heterogeneous impact across patient populations. It is through this more granular research design that we will develop a body of knowledge that can more effectively guide the redesign of primary care practice.

It is important to note that much of the previous literature focused on a general population, not the chronically ill populations we studied, who have higher medical care utilization and generate more costs. In addition, we compared clinics that have all met minimum standards as PCMHs using the Minnesota $\mathrm{HCH}$ criteria; the variance was in stage of that transformation, not whether the clinic was certified as a medical home.

Our work does have some design limitations restricting our ability to infer causality. With only 2010 utilization data, we were unable to use a difference-in-differences framework. In addition, there may have been recall problems for the PPC-RS questions about status 3 years before the survey, although there is no reason to think differences in recall bias would be systematic. Finally, because data were provided by health plans, we were unable to control for sociodemographic variables such as income and race, or to evaluate the impact of PCMH transformation on self-pay patients. Because of the restrictions in our ability to make causal statements, we do not interpret our findings, for example, we do not discuss the implications of fewer primary care outpatient visits. Our contribution is documentation of differences in the transformation-utilization association by transformation domain and population; we hope this motivates future research using granular $\mathrm{PCMH}$ transformation measures.

Nevertheless, this work provides an important contribution by highlighting the differences in utilization across patient populations and transformation domains and showing the importance of the maturity of that transformation. This information should be of value to practice leaders who are eager 
to focus on changes that are likely to have the most impact. It also highlights for researchers the importance of careful measurement of specific domains of transformed care patterns if they wish to fully understand the impact of these changes.

The authors are grateful for the cooperation of the Minnesota Department of Health throughout this study and for the cooperation of the leaders of the certified health care homes in Minnesota with the transformation measurement. This analysis would not have been possible without the extraordinary cooperation of Minnesota Community Measurement and the payers who provided the utilization data: Blue Cross and Blue Shield of Minnesota, HealthPartners, Medica, and the Minnesota Department of Human Services.

\section{References}

1. Hoff T, Weller W, DePuccio M. The patient-centered medical home: a review of recent research. Med Care Res Rev 2012;69:619-44.

2. Peikes D, Zutshi A, Genevro JL, Parchman ML, Meyers DS. Early evaluations of the medical home: building on a promising start. Am J Manag Care 2012;18:105-16.

3. Jackson GL, Powers BJ, Chatterjee R, et al. Improving patient care. The patient centered medical home. A systematic review. Ann Intern Med 2013;158:16978.

4. Ackroyd SA, Wexler DJ. Effectiveness of diabetes interventions in the patient-centered medical home. Curr Diab Rep 2014;14:471.

5. van Hasselt M, McCall N, Keyes V, Wensky SG, Smith KW. Total cost of care lower among Medicare fee-for-service beneficiaries receiving care from patient-centered medical homes. Health Serv Res 2015;50:253-72.

6. Flottemesch TJ, Anderson LH, Solberg LI, Fontaine $\mathrm{P}$, Asche SE. Patient-centered medical home cost reductions limited to complex patients. Am J Manag Care 2012;18:677-86.

7. Cronholm PF, Shea JA, Werner RM, et al. The patient centered medical home: mental models and practice culture driving the transformation process. J Gen Intern Med 2013;28:1195-201.
8. Solberg LI, Crain AL, Tillema J, Scholle SH, Fontaine $\mathrm{P}$, Whitebird R. Medical home transformation: a gradual process and a continuum of attainment. Ann Fam Med 2013;11(Suppl 1):S108-14.

9. DeVries A, Li CH, Sridhar G, Hummel JR, Breidbart S, Barron JJ. Impact of medical homes on quality, healthcare utilization, and costs. Am J Manag Care 2012;18:534-44.

10. Rosenthal MB, Friedberg MW, Singer SJ, Eastman D, Li Z, Schneider EC. Effect of a multipayer patient-centered medical home on health care utilization and quality: the Rhode Island Chronic Care Sustainability Initiative pilot program. JAMA Intern Med 2013;173:1907-13.

11. Reid RJ, Coleman K, Johnson EA, et al. The Group Health medical home at year two: cost savings, higher patient satisfaction, and less burnout for providers. Health Aff (Millwood) 2010;29:835-43.

12. Friedberg $M W$, Schneider EC, Rosenthal MB, Volpp KG, Werner RM. Association between participation in a multipayer medical home intervention and changes in quality, utilization, and costs of care. JAMA 2014;311:815-25.

13. Wang QC, Chawla R, Colombo CM, Snyder RL, Nigam S. Patient-centered medical home impact on health plan members with diabetes. J Public Health Manag Pract 2014;20:E12-20.

14. Philpot LM, Stockbridge EL, Padrón NA, Pagan JA. Patient-centered medical home features and health care expenditures of Medicare beneficiaries with chronic disease dyads. Popul Health Manag 2015 Oct 6 [Epub ahead of print].

15. Burton RA, Devers KJ, Berenson RA. Patient-centered medical home recognition tools: a comparison of ten surveys' content and operational details. Washington, DC: The Urban Institute, Health Policy Center; 2012.

16. HealthPartners. TCOC toolkit. 2014. Available from: http://healthpartners.com/hp/about/tcoc.

17. Perkins AJ, Kroenke K, Unutzer J, et al. Common comorbidity scales were similar in their ability to predict health care costs and mortality. J Clin Epidemiol 2004;57:1040-8. 
Table A1. Marginal Effect of Increasing Maturity in Overall Physician Practice Connections-Readiness Survey (Relative to Early Stage Transformation) by Patient Comorbidity Status

\begin{tabular}{|c|c|c|}
\hline & \multicolumn{2}{|c|}{ Marginal Effect of Maturity on Utilization Measures ( $P$ Value) } \\
\hline & Intermediate-Stage Transformation & Late-Stage Transformation \\
\hline \multicolumn{3}{|l|}{ Diabetes Mellitus } \\
\hline \multicolumn{3}{|l|}{ Total utilization* } \\
\hline Average across comorbidity statuses & $0.040(.407)$ & $0.079(.151)$ \\
\hline 0 Comorbidities & $0.066(.272)$ & $0.095(.115)$ \\
\hline 1 Comorbidity & $-0.011(.876)$ & $0.030(.679)$ \\
\hline$\geq 2$ Comorbidities & $-0.026(.752)$ & $0.083(.613)$ \\
\hline \multicolumn{3}{|l|}{ Number of prescriptions* } \\
\hline Average across comorbidity statuses & $0.028(.374)$ & $0.039(.444)$ \\
\hline 0 Comorbidities & $0.051(.230)$ & $0.061(.225)$ \\
\hline 1 Comorbidity & $-0.028(.511)$ & $-0.009(.904)$ \\
\hline$\geq 2$ Comorbidities & $0.003(.959)$ & $-0.009(.922)$ \\
\hline \multicolumn{3}{|l|}{ Number of outpatient visits* } \\
\hline Average across comorbidity statuses & $-0.078(.231)$ & $-0.151(.020)$ \\
\hline 0 Comorbidities & $-0.047(.560)$ & $-0.147(.075)$ \\
\hline 1 Comorbidity & $-0.130(.030)$ & $-0.172(.004)$ \\
\hline$\geq 2$ Comorbidities & $-0.184(.005)$ & $-0.124(.172)$ \\
\hline \multicolumn{3}{|l|}{$\geq 1$ Inpatient admission $^{\dagger}$} \\
\hline Average across comorbidity statuses & $0.007(.600)$ & $0.002(.854)$ \\
\hline 0 Comorbidities & $0.000(.992)$ & $-0.005(.620)$ \\
\hline 1 Comorbidity & $0.011(.718)$ & $0.007(.821)$ \\
\hline$\geq 2$ Comorbidities & $0.061(.248)$ & $0.066(.297)$ \\
\hline \multicolumn{3}{|l|}{$\geq 1$ Emergency department visit ${ }^{\dagger}$} \\
\hline Average across comorbidity statuses & $0.012(.498)$ & $0.024(.239)$ \\
\hline 0 Comorbidities & $0.014(.362)$ & $0.014(.401)$ \\
\hline 1 Comorbidity & $0.036(.431)$ & $0.064(.179)$ \\
\hline$\geq 2$ Comorbidities & $-0.074(.126)$ & $-0.009(.855)$ \\
\hline \multicolumn{3}{|l|}{ Cardiovascular disease } \\
\hline \multicolumn{3}{|l|}{ Total utilization* } \\
\hline Average across comorbidity statuses & $-0.035(.607)$ & $-0.072(.505)$ \\
\hline 0 Comorbidities & $-0.076(.349)$ & $-0.175(.107)$ \\
\hline 1 Comorbidity & $0.055(.510)$ & $0.159(.294)$ \\
\hline$\geq 2$ Comorbidities & $-0.111(.424)$ & $-0.256(.147)$ \\
\hline \multicolumn{3}{|l|}{ Number of prescriptions* } \\
\hline Average across comorbidity statuses & $-0.046(.287)$ & $-0.047(.543)$ \\
\hline 0 Comorbidities & $-0.083(.234)$ & $-0.099(.309)$ \\
\hline 1 Comorbidity & $0.040(.388)$ & $0.047(.579)$ \\
\hline$\geq 2$ Comorbidities & $-0.125(.141)$ & $-0.089(.401)$ \\
\hline \multicolumn{3}{|l|}{ Number of outpatient visits* } \\
\hline Average across comorbidity statuses & $-0.167(.002)$ & $-0.201(.010)$ \\
\hline 0 Comorbidities & $-0.198(.004)$ & $-0.340(.000)$ \\
\hline 1 Comorbidity & $-0.055(.530)$ & $0.029(.835)$ \\
\hline$\geq 2$ Comorbidities & $-0.342(.004)$ & $-0.261(.024)$ \\
\hline \multicolumn{3}{|l|}{$\geq 1$ Inpatient admission $^{\dagger}$} \\
\hline Average across comorbidity statuses & $0.029(.362)$ & $-0.001(.985)$ \\
\hline 0 Comorbidities & $0.014(.532)$ & $-0.021(.377)$ \\
\hline 1 Comorbidity & $0.064(.177)$ & $0.073(.199)$ \\
\hline$\geq 2$ Comorbidities & $-0.001(.992)$ & $-0.105(.258)$ \\
\hline
\end{tabular}




\begin{tabular}{lcr}
\hline & \multicolumn{2}{c}{ Marginal Effect of Maturity on Utilization Measures $(P$ Value $)$} \\
\cline { 2 - 3 } & Intermediate-Stage Transformation & Late-Stage Transformation \\
\hline Cardiovascular disease & & \\
$\geq 1$ Emergency department visit ${ }^{\dagger}$ & $0.009(.802)$ & $-0.012(.752)$ \\
$\quad$ Average across comorbidity statuses & $-0.038(.287)$ & $-0.104(.008)$ \\
0 Comorbidities & $0.062(.143)$ & $0.100(.057)$ \\
1 Comorbidity & $0.061(.578)$ & $0.066(.520)$ \\
$\geq 2$ Comorbidities & & \\
\hline
\end{tabular}

*Approximate percentage change $(0.10=10 \%)$ in outcome variable when clinic moves from early stage to intermediate- or late-stage transformation.

${ }^{\dagger}$ Estimated percentage-point change $(0.10=10$ percentage points $)$ in the probability of outcome when a clinic moves from early stage to intermediate- or late-stage transformation. 
Table A2. Marginal Effect of Increasing Maturity by Patient-Centered Medical Home Domain (Relative to Early Stage Transformation)

\begin{tabular}{|c|c|c|}
\hline & \multicolumn{2}{|c|}{ Marginal Effect of Maturity on Utilization Measures ( $P$ Value) } \\
\hline & Intermediate-Stage Domain & Late-Stage Domain \\
\hline \multicolumn{3}{|l|}{ Diabetes mellitus } \\
\hline \multicolumn{3}{|l|}{ Total utilization* } \\
\hline Overall impact of all domains (PPC-RS) & $0.040(.407)$ & $0.079(.151)$ \\
\hline Health care organization & $0.140(.063)$ & $0.152(.025)$ \\
\hline Delivery system redesign & $0.026(.435)$ & $0.102(.066)$ \\
\hline Clinical information system & $0.070(.134)$ & $-0.005(.940)$ \\
\hline Decision support & $-0.180(.001)$ & $-0.218(.000)$ \\
\hline Self-management system & $0.103(.007)$ & $0.149(.011)$ \\
\hline \multicolumn{3}{|l|}{ Number of prescriptions* } \\
\hline Overall impact of all domains (PPC-RS) & $0.028(.374)$ & $0.039(.444)$ \\
\hline Health care organization & $-0.001(.991)$ & $-0.001(.985)$ \\
\hline Delivery system redesign & $0.037(.330)$ & $0.160(.015)$ \\
\hline Clinical information system & $0.059(.225)$ & $0.010(.879)$ \\
\hline Decision support & $0.012(.816)$ & $-0.101(.089)$ \\
\hline Self-management system & $-0.009(.849)$ & $0.054(.412)$ \\
\hline \multicolumn{3}{|l|}{ Number of outpatient visits* } \\
\hline Overall impact of all domains (PPC-RS) & $-0.078(.231)$ & $-0.151(.020)$ \\
\hline Health care organization & $0.160(.108)$ & $0.150(.097)$ \\
\hline Delivery system redesign & $0.063(.132)$ & $0.092(.153)$ \\
\hline Clinical information system & $-0.083(.101)$ & $-0.303(.000)$ \\
\hline Decision support & $-0.137(.160)$ & $-0.102(.293)$ \\
\hline Self-management system & $0.085(.047)$ & $0.093(.168)$ \\
\hline \multicolumn{3}{|l|}{$\geq 1$ Inpatient admission $^{\dagger}$} \\
\hline Overall impact of all domains (PPC-RS) & $0.007(.600)$ & $0.002(.854)$ \\
\hline Health care organization & $0.021(.253)$ & $0.037(.035)$ \\
\hline Delivery system redesign & $-0.003(.749)$ & $0.005(.674)$ \\
\hline Clinical information system & $0.019(.117)$ & $0.004(.758)$ \\
\hline Decision support & $-0.033(.078)$ & $-0.038(.045)$ \\
\hline Self-management system & $0.015(.223)$ & $0.017(.283)$ \\
\hline \multicolumn{3}{|l|}{$\geq 1$ Emergency department visit $^{\dagger}$} \\
\hline Overall impact of all domains (PPC-RS) & $0.012(.498)$ & $0.024(.239)$ \\
\hline Health care organization & $0.025(.099)$ & $0.027(.068)$ \\
\hline Delivery system redesign & $0.016(.192)$ & $-0.020(.264)$ \\
\hline Clinical information system & $0.014(.296)$ & $0.012(.458)$ \\
\hline Decision support & $0.003(.882)$ & $0.020(.386)$ \\
\hline Self-management system & $-0.014(.317)$ & $0.009(.653)$ \\
\hline \multicolumn{3}{|l|}{ Cardiovascular disease } \\
\hline \multicolumn{3}{|l|}{ Total utilization* } \\
\hline Overall impact of all domains (PPC-RS) & $-0.035(.607)$ & $-0.072(.505)$ \\
\hline Health care organization & $0.041(.696)$ & $0.003(.976)$ \\
\hline Delivery system redesign & $0.001(.988)$ & $-0.066(.638)$ \\
\hline Clinical information system & $0.097(.330)$ & $0.065(.601)$ \\
\hline Decision support & $0.013(.923)$ & $-0.003(.982)$ \\
\hline Self-management system & $-0.038(.697)$ & $-0.021(.866)$ \\
\hline \multicolumn{3}{|l|}{ Number of prescriptions* } \\
\hline Overall impact of all domains (PPC-RS) & $-0.046(.287)$ & $-0.047(.543)$ \\
\hline Health care organization & $-0.040(.607)$ & $-0.014(.855)$ \\
\hline Delivery system redesign & $-0.083(.057)$ & $-0.149(.072)$ \\
\hline
\end{tabular}




\begin{tabular}{|c|c|c|}
\hline & \multicolumn{2}{|c|}{ Marginal Effect of Maturity on Utilization Measures ( $P$ Value) } \\
\hline & Intermediate-Stage Domain & Late-Stage Domain \\
\hline \multicolumn{3}{|l|}{ Cardiovascular disease } \\
\hline \multicolumn{3}{|l|}{ Number of prescriptions* } \\
\hline Clinical information system & $0.215(.004)$ & $0.151(.104)$ \\
\hline Decision support & $-0.165(.096)$ & $-0.256(.012)$ \\
\hline Self-management system & $0.036(.605)$ & $0.184(.052)$ \\
\hline \multicolumn{3}{|l|}{ Number of outpatient visits* } \\
\hline Overall impact of all domains (PPC-RS) & $-0.167(.002)$ & $-0.201(.010)$ \\
\hline Health care organization & $0.198(.031)$ & $0.057(.486)$ \\
\hline Delivery system redesign & $0.009(.895)$ & $-0.141(.209)$ \\
\hline Clinical information system & $0.006(.964)$ & $-0.020(.866)$ \\
\hline Decision support & $-0.133(.343)$ & $-0.066(.664)$ \\
\hline Self-management system & $0.027(.757)$ & $0.036(.770)$ \\
\hline \multicolumn{3}{|l|}{$\geq 1$ Inpatient admission $^{\dagger}$} \\
\hline Overall impact of all domains (PPC-RS) & $0.029(.362)$ & $-0.001(.985)$ \\
\hline Health care organization & $-0.026(.662)$ & $-0.033(.554)$ \\
\hline Delivery system redesign & $0.003(.890)$ & $-0.011(.821)$ \\
\hline Clinical information system & $-0.013(.713)$ & $-0.001(.986)$ \\
\hline Decision support & $0.081(.067)$ & $0.069(.121)$ \\
\hline Self-management system & $-0.027(.476)$ & $-0.042(.353)$ \\
\hline \multicolumn{3}{|l|}{$\geq 1$ Emergency department visit ${ }^{\dagger}$} \\
\hline Overall impact of all domains (PPC-RS) & $0.009(.802)$ & $-0.012(.752)$ \\
\hline Health care organization & $-0.008(.928)$ & $-0.013(.873)$ \\
\hline Delivery system redesign & $-0.041(.068)$ & $-0.017(.641)$ \\
\hline Clinical information system & $-0.040(.332)$ & $-0.032(.479)$ \\
\hline Decision support & $0.109(.033)$ & $0.105(.032)$ \\
\hline Self-management system & $-0.027(.497)$ & $-0.041(.428)$ \\
\hline
\end{tabular}

*Approximate percentage change $(0.10=10 \%)$ in outcome variable when clinic moves from early stage to intermediate- or late-stage transformation.

${ }^{\dagger}$ Estimated percentage-point change $(0.10=10$ percentage points $)$ in the probability of outcome when a clinic moves from early stage to intermediate- or late-stage transformation.

PPC-RS, Physician Practice Connections-Readiness Survey. 
Table A3. Marginal Effect of Increasing Maturity by Patient-Centered Medical Home Domain (Relative to Early Stage Transformation) by Patient Comorbidity Status

\begin{tabular}{|c|c|c|}
\hline & \multicolumn{2}{|c|}{ Marginal Effect of Maturity on Utilization Measures ( $P$ Value) } \\
\hline & Intermediate-Stage Domain & Late-Stage Domain \\
\hline \multicolumn{3}{|l|}{ Diabetes mellitus } \\
\hline \multicolumn{3}{|l|}{ Total utilization* } \\
\hline \multicolumn{3}{|l|}{ Health care organization } \\
\hline Average across comorbidity statuses & $0.140(.063)$ & $0.152(.025)$ \\
\hline 0 Comorbidities & $0.115(.113)$ & $0.121(.055)$ \\
\hline 1 Comorbidity & $0.179(.094)$ & $0.197(.040)$ \\
\hline$\geq 2$ Comorbidities & $0.279(.054)$ & $0.336(.028)$ \\
\hline \multicolumn{3}{|l|}{ Delivery system redesign } \\
\hline Average across comorbidity statuses & $0.026(.435)$ & $0.102(.066)$ \\
\hline 0 Comorbidities & $0.043(.124)$ & $0.091(.054)$ \\
\hline 1 Comorbidity & $-0.007(.906)$ & $0.097(.222)$ \\
\hline$\geq 2$ Comorbidities & $-0.016(.907)$ & $0.234(.301)$ \\
\hline \multicolumn{3}{|l|}{ Clinical information system } \\
\hline Average across comorbidity statuses & $0.070(.134)$ & $-0.005(.940)$ \\
\hline 0 Comorbidities & $0.062(.171)$ & $0.011(.830)$ \\
\hline 1 Comorbidity & $0.050(.533)$ & $-0.038(.670)$ \\
\hline$\geq 2$ Comorbidities & $0.247(.284)$ & $-0.024(.924)$ \\
\hline \multicolumn{3}{|l|}{ Decision support } \\
\hline Average across comorbidity statuses & $-0.180(.001)$ & $-0.218(.000)$ \\
\hline 0 Comorbidities & $-0.194(.001)$ & $-0.248(.000)$ \\
\hline 1 Comorbidity & $-0.182(.082)$ & $-0.204(.098)$ \\
\hline$\geq 2$ Comorbidities & $-0.063(.797)$ & $-0.015(.947)$ \\
\hline \multicolumn{3}{|l|}{ Self-management system } \\
\hline Average across comorbidity statuses & $0.103(.007)$ & $0.149(.011)$ \\
\hline 0 Comorbidities & $0.129(.001)$ & $0.166(.003)$ \\
\hline 1 Comorbidity & $0.117(.116)$ & $0.160(.101)$ \\
\hline$\geq 2$ Comorbidities & $-0.207(.095)$ & $-0.036(.877)$ \\
\hline \multicolumn{3}{|l|}{ Number of prescriptions* } \\
\hline \multicolumn{3}{|l|}{ Health care organization } \\
\hline Average across comorbidity statuses & $-0.001(.991)$ & $-0.001(.985)$ \\
\hline 0 Comorbidities & $-0.011(.839)$ & $-0.004(.943)$ \\
\hline 1 Comorbidity & $0.007(.951)$ & $0.011(.916)$ \\
\hline$\geq 2$ Comorbidities & $-0.023(.855)$ & $-0.033(.795)$ \\
\hline \multicolumn{3}{|l|}{ Delivery system redesign } \\
\hline Average across comorbidity statuses & $0.037(.330)$ & $0.160(.015)$ \\
\hline 0 Comorbidities & $0.036(.368)$ & $0.107(.102)$ \\
\hline 1 Comorbidity & $0.041(.508)$ & $0.263(.008)$ \\
\hline$\geq 2$ Comorbidities & $0.101(.179)$ & $0.383(.001)$ \\
\hline \multicolumn{3}{|l|}{ Clinical information system } \\
\hline Average across comorbidity statuses & $0.059(.225)$ & $0.010(.879)$ \\
\hline 0 Comorbidities & $0.048(.375)$ & $0.008(.898)$ \\
\hline 1 Comorbidity & $0.083(.303)$ & $0.049(.615)$ \\
\hline$\geq 2$ Comorbidities & $0.035(.737)$ & $-0.077(.534)$ \\
\hline \multicolumn{3}{|l|}{ Decision support } \\
\hline Average across comorbidity statuses & $0.012(.816)$ & $-0.101(.089)$ \\
\hline 0 Comorbidities & $0.087(.133)$ & $-0.060(.328)$ \\
\hline 1 Comorbidity & $-0.135(.113)$ & $-0.184(.055)$ \\
\hline$\geq 2$ Comorbidities & $-0.194(.026)$ & $-0.205(.077)$ \\
\hline
\end{tabular}




\begin{tabular}{|c|c|c|}
\hline & \multicolumn{2}{|c|}{ Marginal Effect of Maturity on Utilization Measures ( $P$ Value) } \\
\hline & Intermediate-Stage Domain & Late-Stage Domain \\
\hline \multicolumn{3}{|l|}{ Diabetes mellitus } \\
\hline \multicolumn{3}{|l|}{ Number of prescriptions* } \\
\hline \multicolumn{3}{|l|}{ Self-management system } \\
\hline Average across comorbidity statuses & $-0.009(.849)$ & $0.054(.412)$ \\
\hline 0 Comorbidities & $-0.018(.706)$ & $0.090(.192)$ \\
\hline 1 Comorbidity & $-0.015(.817)$ & $-0.044(.668)$ \\
\hline$\geq 2$ Comorbidities & $0.042(.618)$ & $-0.033(.805)$ \\
\hline \multicolumn{3}{|l|}{ Number of outpatient visits* } \\
\hline \multicolumn{3}{|l|}{ Health care organization } \\
\hline Average across comorbidity statuses & $0.160(.108)$ & $0.150(.097)$ \\
\hline 0 Comorbidities & $0.121(.282)$ & $0.125(.228)$ \\
\hline 1 Comorbidity & $0.175(.098)$ & $0.130(.149)$ \\
\hline$\geq 2$ Comorbidities & $0.457(.000)$ & $0.452(.000)$ \\
\hline \multicolumn{3}{|l|}{ Delivery system redesign } \\
\hline Average across comorbidity statuses & $0.063(.132)$ & $0.092(.153)$ \\
\hline 0 Comorbidities & $0.059(.154)$ & $0.080(.251)$ \\
\hline 1 Comorbidity & $0.080(.101)$ & $0.081(.364)$ \\
\hline$\geq 2$ Comorbidities & $0.064(.482)$ & $0.325(.019)$ \\
\hline \multicolumn{3}{|l|}{ Clinical information system } \\
\hline Average across comorbidity statuses & $-0.083(.101)$ & $-0.303(.000)$ \\
\hline 0 Comorbidities & $-0.064(.211)$ & $-0.316(.000)$ \\
\hline 1 Comorbidity & $-0.140(.145)$ & $-0.266(.003)$ \\
\hline$\geq 2$ Comorbidities & $-0.024(.842)$ & $-0.258(.063)$ \\
\hline \multicolumn{3}{|l|}{ Decision support } \\
\hline Average across comorbidity statuses & $-0.137(.160)$ & $-0.102(.293)$ \\
\hline 0 Comorbidities & $-0.162(.174)$ & $-0.144(.229)$ \\
\hline 1 Comorbidity & $-0.100(.374)$ & $-0.039(.733)$ \\
\hline$\geq 2$ Comorbidities & $-0.084(.478)$ & $0.045(.706)$ \\
\hline \multicolumn{3}{|l|}{ Self-management system } \\
\hline Average across comorbidity statuses & $0.085(.047)$ & $0.093(.168)$ \\
\hline 0 Comorbidities & $0.120(.019)$ & $0.128(.088)$ \\
\hline 1 Comorbidity & $0.059(.315)$ & $0.048(.629)$ \\
\hline$\geq 2$ Comorbidities & $-0.156(.034)$ & $-0.144(.306)$ \\
\hline \multicolumn{3}{|l|}{$\geq 1$ Inpatient $_{\text {admission }}{ }^{\dagger}$} \\
\hline \multicolumn{3}{|l|}{ Health care organization } \\
\hline Average across comorbidity statuses & $0.021(.253)$ & $0.037(.035)$ \\
\hline 0 Comorbidities & $0.029(.006)$ & $0.034(.000)$ \\
\hline 1 Comorbidity & $0.035(.460)$ & $0.041(.337)$ \\
\hline$\geq 2$ Comorbidities & $-0.077(.434)$ & $0.043(.676)$ \\
\hline \multicolumn{3}{|l|}{ Delivery system redesign } \\
\hline Average across comorbidity statuses & $-0.003(.749)$ & $0.005(.674)$ \\
\hline 0 Comorbidities & $0.002(.765)$ & $0.009(.469)$ \\
\hline 1 Comorbidity & $-0.025(.326)$ & $-0.030(.408)$ \\
\hline$\geq 2$ Comorbidities & $-0.005(.951)$ & $0.066(.525)$ \\
\hline \multicolumn{3}{|l|}{ Clinical information system } \\
\hline Average across comorbidity statuses & $0.019(.117)$ & $0.004(.758)$ \\
\hline 0 Comorbidities & $-0.001(.963)$ & $-0.006(.643)$ \\
\hline 1 Comorbidity & $0.073(.013)$ & $0.027(.291)$ \\
\hline$\geq 2$ Comorbidities & $0.068(.501)$ & $0.006(.959)$ \\
\hline
\end{tabular}




\begin{tabular}{|c|c|c|}
\hline & \multicolumn{2}{|c|}{ Marginal Effect of Maturity on Utilization Measures ( $P$ Value) } \\
\hline & Intermediate-Stage Domain & Late-Stage Domain \\
\hline \multicolumn{3}{|l|}{ Diabetes mellitus } \\
\hline \multicolumn{3}{|l|}{$\geq 1$ Inpatient admission $^{\dagger}$} \\
\hline \multicolumn{3}{|l|}{ Decision support } \\
\hline Average across comorbidity statuses & $-0.033(.078)$ & $-0.038(.045)$ \\
\hline 0 Comorbidities & $-0.035(.041)$ & $-0.024(.175)$ \\
\hline 1 Comorbidity & $-0.042(.468)$ & $-0.103(.080)$ \\
\hline$\geq 2$ Comorbidities & $0.010(.926)$ & $0.017(.869)$ \\
\hline \multicolumn{3}{|l|}{ Self-management system } \\
\hline Average across comorbidity statuses & $0.015(.223)$ & $0.017(.283)$ \\
\hline 0 Comorbidities & $0.024(.020)$ & $0.004(.736)$ \\
\hline 1 Comorbidity & $0.013(.546)$ & $0.104(.015)$ \\
\hline$\geq 2$ Comorbidities & $-0.055(.433)$ & $-0.062(.595)$ \\
\hline \multicolumn{3}{|l|}{$\geq 1$ Emergency department visit ${ }^{\dagger}$} \\
\hline \multicolumn{3}{|l|}{ Health care organization } \\
\hline Average across comorbidity statuses & $0.025(.099)$ & $0.027(.068)$ \\
\hline 0 Comorbidities & $0.016(.160)$ & $0.019(.061)$ \\
\hline 1 Comorbidity & $-0.002(.959)$ & $-0.005(.885)$ \\
\hline$\geq 2$ Comorbidities & $0.228(.006)$ & $0.210(.009)$ \\
\hline \multicolumn{3}{|l|}{ Delivery system redesign } \\
\hline Average across comorbidity statuses & $0.016(.192)$ & $-0.020(.264)$ \\
\hline 0 Comorbidities & $0.025(.033)$ & $-0.005(.793)$ \\
\hline 1 Comorbidity & $-0.009(.755)$ & $-0.078(.038)$ \\
\hline$\geq 2$ Comorbidities & $-0.016(.706)$ & $0.004(.939)$ \\
\hline \multicolumn{3}{|l|}{ Clinical information system } \\
\hline Average across comorbidity statuses & $0.014(.296)$ & $0.012(.458)$ \\
\hline 0 Comorbidities & $0.040(.005)$ & $0.015(.283)$ \\
\hline 1 Comorbidity & $-0.029(.517)$ & $0.040(.346)$ \\
\hline$\geq 2$ Comorbidities & $-0.079(.280)$ & $-0.079(.283)$ \\
\hline \multicolumn{3}{|l|}{ Decision support } \\
\hline Average across comorbidity statuses & $0.003(.882)$ & $0.020(.386)$ \\
\hline 0 Comorbidities & $-0.047(.005)$ & $-0.028(.150)$ \\
\hline 1 Comorbidity & $0.098(.059)$ & $0.124(.028)$ \\
\hline$\geq 2$ Comorbidities & $0.114(.210)$ & $0.094(.301)$ \\
\hline \multicolumn{3}{|l|}{ Self-management system } \\
\hline Average across comorbidity statuses & $-0.014(.317)$ & $0.009(.653)$ \\
\hline 0 Comorbidities & $-0.007(.628)$ & $0.013(.563)$ \\
\hline 1 Comorbidity & $-0.007(.822)$ & $-0.002(.971)$ \\
\hline$\geq 2$ Comorbidities & $-0.093(.065)$ & $-0.007(.926)$ \\
\hline \multicolumn{3}{|l|}{ Cardiovascular disease } \\
\hline \multicolumn{3}{|l|}{ Total utilization* } \\
\hline \multicolumn{3}{|l|}{ Health care organization } \\
\hline Average across comorbidity statuses & $0.041(.696)$ & $0.003(.976)$ \\
\hline 0 Comorbidities & $0.056(.733)$ & $0.021(.896)$ \\
\hline 1 Comorbidity & $-0.029(.778)$ & $-0.042(.663)$ \\
\hline$\geq 2$ Comorbidities & $0.231(.413)$ & $0.136(.605)$ \\
\hline \multicolumn{3}{|l|}{ Delivery system redesign } \\
\hline Average across comorbidity statuses & $0.001(.988)$ & $-0.066(.638)$ \\
\hline 0 Comorbidities & $0.062(.495)$ & $-0.036(.800)$ \\
\hline 1 Comorbidity & $-0.098(.262)$ & $-0.321(.157)$ \\
\hline$\geq 2$ Comorbidities & $0.055(.741)$ & $0.425(.076)$ \\
\hline
\end{tabular}




\begin{tabular}{|c|c|c|}
\hline & \multicolumn{2}{|c|}{ Marginal Effect of Maturity on Utilization Measures ( $P$ Value) } \\
\hline & Intermediate-Stage Domain & Late-Stage Domain \\
\hline \multicolumn{3}{|l|}{ Cardiovascular disease } \\
\hline \multicolumn{3}{|l|}{ Total utilization* } \\
\hline \multicolumn{3}{|l|}{ Clinical information system } \\
\hline Average across comorbidity statuses & $0.097(.330)$ & $0.065(.601)$ \\
\hline No comorbidities & $0.105(.351)$ & $0.040(.760)$ \\
\hline One comorbidity & $0.224(.146)$ & $0.339(.055)$ \\
\hline Two or more comorbidities & $-0.191(.450)$ & $-0.354(.082)$ \\
\hline \multicolumn{3}{|l|}{ Decision support } \\
\hline Average across comorbidity statuses & $0.013(.923)$ & $-0.003(.982)$ \\
\hline 0 Comorbidities & $-0.038(.825)$ & $-0.048(.753)$ \\
\hline 1 Comorbidity & $-0.079(.680)$ & $-0.142(.467)$ \\
\hline$\geq 2$ Comorbidities & $0.197(.516)$ & $0.256(.453)$ \\
\hline \multicolumn{3}{|l|}{ Self-management system } \\
\hline Average across comorbidity statuses & $-0.038(.697)$ & $-0.021(.866)$ \\
\hline 0 Comorbidities & $-0.093(.482)$ & $-0.112(.474)$ \\
\hline 1 Comorbidity & $0.142(.279)$ & $0.256(.176)$ \\
\hline$\geq 2$ Comorbidities & $-0.221(.335)$ & $-0.355(.298)$ \\
\hline \multicolumn{3}{|l|}{ Number of prescriptions* } \\
\hline \multicolumn{3}{|l|}{ Health care organization } \\
\hline Average across comorbidity statuses & $-0.040(.607)$ & $-0.014(.855)$ \\
\hline 0 Comorbidities & $0.007(.932)$ & $0.004(.956)$ \\
\hline 1 Comorbidity & $-0.058(.535)$ & $-0.015(.861)$ \\
\hline$\geq 2$ Comorbidities & $-0.216(.025)$ & $-0.154(.110)$ \\
\hline \multicolumn{3}{|l|}{ Delivery system redesign } \\
\hline Average across comorbidity statuses & $-0.083(.057)$ & $-0.149(.072)$ \\
\hline 0 Comorbidities & $-0.180(.001)$ & $-0.267(.008)$ \\
\hline 1 Comorbidity & $-0.021(.734)$ & $-0.123(.285)$ \\
\hline$\geq 2$ Comorbidities & $0.186(.039)$ & $0.273(0036)$ \\
\hline \multicolumn{3}{|l|}{ Clinical information system } \\
\hline Average across comorbidity statuses & $0.215(.004)$ & $0.151(.104)$ \\
\hline 0 Comorbidities & $0.311(.002)$ & $0.152(.201)$ \\
\hline 1 Comorbidity & $0.131(.155)$ & $0.201(.064)$ \\
\hline$\geq 2$ Comorbidities & $-0.148(.449)$ & $-0.004(.981)$ \\
\hline \multicolumn{3}{|l|}{ Decision support } \\
\hline Average across comorbidity statuses & $-0.165(.096)$ & $-0.256(.012)$ \\
\hline 0 Comorbidities & $-0.196(.127)$ & $-0.366(.005)$ \\
\hline 1 Comorbidity & $-0.154(.192)$ & $-0.060(.623)$ \\
\hline$\geq 2$ Comorbidities & $-0.033(.884)$ & $-0.146(.524)$ \\
\hline \multicolumn{3}{|l|}{ Self-management system } \\
\hline Average across comorbidity statuses & $0.036(.605)$ & $0.184(.052)$ \\
\hline 0 Comorbidities & $0.068(.413)$ & $0.372(.002)$ \\
\hline 1 Comorbidity & $0.087(.271)$ & $-0.002(.987)$ \\
\hline$\geq 2$ Comorbidities & $-0.155(.213)$ & $-0.261(.217)$ \\
\hline \multicolumn{3}{|l|}{ Number of outpatient visits* } \\
\hline \multicolumn{3}{|l|}{ Health care organization } \\
\hline Average across comorbidity statuses & $0.198(.031)$ & $0.057(.486)$ \\
\hline 0 Comorbidities & $0.290(.017)$ & $0.093(.457)$ \\
\hline 1 Comorbidity & $0.068(.611)$ & $-0.024(.819)$ \\
\hline$\geq 2$ Comorbidities & $0.378(.165)$ & $0.348(.184)$ \\
\hline
\end{tabular}




\begin{tabular}{|c|c|c|}
\hline & \multicolumn{2}{|c|}{ Marginal Effect of Maturity on Utilization Measures ( $P$ Value) } \\
\hline & Intermediate-Stage Domain & Late-Stage Domain \\
\hline \multicolumn{3}{|l|}{ Cardiovascular disease } \\
\hline \multicolumn{3}{|l|}{ Number of outpatient visits* } \\
\hline \multicolumn{3}{|l|}{ Delivery system redesign } \\
\hline Average across comorbidity statuses & $0.009(.895)$ & $-0.141(.209)$ \\
\hline 0 Comorbidities & $0.006(.947)$ & $-0.137(.280)$ \\
\hline 1 Comorbidity & $-0.024(.801)$ & $-0.286(.171)$ \\
\hline$\geq 2$ Comorbidities & $0.167(.147)$ & $0.242(.106)$ \\
\hline \multicolumn{3}{|l|}{ Clinical information system } \\
\hline Average across comorbidity statuses & $0.006(.964)$ & $-0.020(.866)$ \\
\hline 0 Comorbidities & $0.010(.945)$ & $-0.055(.710)$ \\
\hline 1 Comorbidity & $0.080(.609)$ & $0.107(.514)$ \\
\hline$\geq 2$ Comorbidities & $-0.205(.393)$ & $-0.118(.464)$ \\
\hline \multicolumn{3}{|l|}{ Decision support } \\
\hline Average across comorbidity statuses & $-0.133(.343)$ & $-0.066(.664)$ \\
\hline 0 Comorbidities & $-0.092(.560)$ & $-0.022(.902)$ \\
\hline 1 Comorbidity & $-0.236(.194)$ & $-0.198(.298)$ \\
\hline$\geq 2$ Comorbidities & $-0.191(.485)$ & $-0.082(.783)$ \\
\hline \multicolumn{3}{|l|}{ Self-management system } \\
\hline Average across comorbidity statuses & $0.027(.757)$ & $0.036(.770)$ \\
\hline 0 Comorbidities & $0.000(.999)$ & $-0.044(.760)$ \\
\hline 1 Comorbidity & $0.155(.156)$ & $0.276(.098)$ \\
\hline$\geq 2$ Comorbidities & $-0.145(.376)$ & $-0.319(.249)$ \\
\hline \multicolumn{3}{|l|}{$\geq 1$ Inpatient admission $^{\dagger}$} \\
\hline \multicolumn{3}{|l|}{ Health care organization } \\
\hline Average across comorbidity statuses & $-0.026(.662)$ & $-0.033(.554)$ \\
\hline 0 Comorbidities & $0.001(.987)$ & $0.003(.964)$ \\
\hline 1 Comorbidity & $-0.087(.044)$ & $-0.095(.016)$ \\
\hline$\geq 2$ Comorbidities & $0.109(.558)$ & $0.102(.580)$ \\
\hline \multicolumn{3}{|l|}{ Delivery system redesign } \\
\hline Average across comorbidity statuses & $0.003(.890)$ & $-0.011(.821)$ \\
\hline 0 Comorbidities & $0.045(.127)$ & $0.045(.127)$ \\
\hline 1 Comorbidity & $-0.057(.083)$ & $-0.057(.083)$ \\
\hline$\geq 2$ Comorbidities & $0.018(.804)$ & $0.018(.804)$ \\
\hline \multicolumn{3}{|l|}{ Clinical information system } \\
\hline Average across comorbidity statuses & $-0.013(.713)$ & $-0.001(.986)$ \\
\hline 0 Comorbidities & $-0.006(.893)$ & $0.004(.932)$ \\
\hline 1 Comorbidity & $0.044(.388)$ & $0.112(.025)$ \\
\hline$\geq 2$ Comorbidities & $-0.089(.359)$ & $-0.185(.042)$ \\
\hline \multicolumn{3}{|l|}{ Decision support } \\
\hline Average across comorbidity statuses & $0.081(.067)$ & $0.069(.121)$ \\
\hline 0 Comorbidities & $0.006(.919)$ & $0.014(.785)$ \\
\hline 1 Comorbidity & $0.124(.050)$ & $0.041(.529)$ \\
\hline$\geq 2$ Comorbidities & $0.144(.355)$ & $0.219(.191)$ \\
\hline \multicolumn{3}{|l|}{ Self-management system } \\
\hline Average across comorbidity statuses & $-0.027(.476)$ & $-0.042(.353)$ \\
\hline 0 Comorbidities & $-0.036(.458)$ & $-0.078(.143)$ \\
\hline 1 Comorbidity & $0.011(.824)$ & $0.074(.306)$ \\
\hline$\geq 2$ Comorbidities & $-0.123(.141)$ & $-0.225(.092)$ \\
\hline
\end{tabular}




\begin{tabular}{|c|c|c|}
\hline & \multicolumn{2}{|c|}{ Marginal Effect of Maturity on Utilization Measures ( $P$ Value) } \\
\hline & Intermediate-Stage Domain & Late-Stage Domain \\
\hline \multicolumn{3}{|l|}{ Cardiovascular disease } \\
\hline \multicolumn{3}{|l|}{$\geq 1$ Emergency department visit ${ }^{\dagger}$} \\
\hline \multicolumn{3}{|l|}{ Health care organization } \\
\hline Average across comorbidity statuses & $-0.008(.928)$ & $-0.013(.873)$ \\
\hline 0 Comorbidities & $-0.026(.681)$ & $0.020(.744)$ \\
\hline 1 Comorbidity & $0.011(.855)$ & $-0.024(.682)$ \\
\hline$\geq 2$ Comorbidities & $0.104(.727)$ & $0.033(.911)$ \\
\hline \multicolumn{3}{|l|}{ Delivery system redesign } \\
\hline Average across comorbidity statuses & $-0.041(.068)$ & $-0.017(.641)$ \\
\hline 0 Comorbidities & $-0.037(.232)$ & $-0.072(.105)$ \\
\hline 1 Comorbidity & $-0.039(.215)$ & $0.021(.746)$ \\
\hline$\geq 2$ Comorbidities & $-0.042(.685)$ & $0.110(.390)$ \\
\hline \multicolumn{3}{|l|}{ Clinical information system } \\
\hline Average across comorbidity statuses & $-0.040(.332)$ & $-0.032(.479)$ \\
\hline 0 Comorbidities & $0.027(.522)$ & $0.038(.424)$ \\
\hline 1 Comorbidity & $-0.083(.234)$ & $-0.040(.536)$ \\
\hline$\geq 2$ Comorbidities & $-0.031(.840)$ & $-0.185(.209)$ \\
\hline \multicolumn{3}{|l|}{ Decision support } \\
\hline Average across comorbidity statuses & $0.109(.033)$ & $0.105(.032)$ \\
\hline 0 Comorbidities & $-0.002(.968)$ & $0.015(.763)$ \\
\hline 1 Comorbidity & $0.182(.002)$ & $0.145(.016)$ \\
\hline$\geq 2$ Comorbidities & $0.145(.480)$ & $0.149(.497)$ \\
\hline \multicolumn{3}{|l|}{ Self-management system } \\
\hline Average across comorbidity statuses & $-0.027(.497)$ & $-0.041(.428)$ \\
\hline 0 Comorbidities & $-0.078(.114)$ & $-0.130(.014)$ \\
\hline 1 Comorbidity & $0.027(.543)$ & $0.060(.431)$ \\
\hline$\geq 2$ Comorbidities & $-0.008(.949)$ & $0.083(.690)$ \\
\hline
\end{tabular}

*Approximate percentage change $(0.10=10 \%)$ in outcome variable when a clinic moves from early stage to intermediate- or late-stage transformation.

${ }^{\dagger}$ Estimated percentage-point change $(0.10=10$ percentage points $)$ in probability of outcome when a clinic moves from early stage to intermediate- or late-stage transformation. 